\title{
Design and analysis trends of helicopter rotor systems
}

\author{
INDERJIT CHOPRA
}

Center for Rotorcraft Education and Research, Department of Aerospace Engineering, University of Maryland, College Park, Maryland 20742, USA

\begin{abstract}
To overcome many of the problems associated with conventional articulated rotor systems, new rotor systems are being contemplated. In this paper, the state-of-art technology of advanced rotor systems is assessed. Advanced rotors include hingeless, bearingless, composite, circulation control, tilt and advanced geometry rotors. The paper reviews mathematical modelling, analysis methods, past and recent developments, potential limitations and future research needs in each system. Also, the potential of incorporation of structural optimization methodology and smart structures technology in rotors to improve the efficiency and capabilities of rotorcraft is discussed.
\end{abstract}

Keywords. Articulated rotor systems; structural optimization; rotorcraft; helicopter rotor systems.

\section{Introduction}

Conventional articulated rotor systems, routinely used in current helicopters, suffer from problems that include high vibratory loads, susceptibility to ground resonance instability, low control power, high operating cost and poor performance in high speed and high load conditions. To improve some of these deficiencies, and also to further expand the flight missions of military and civilian helicopters, many new rotor systems are being contemplated. Examples of new rotor systems are: hingeless, bearingless, composite, circulation control, tilt and advanced geometry rotors. Currently, there are numerous drawbacks of these advanced rotor systems that include inadequate analytical tools, new and sometimes severe dynamic problems, insufficient test and flight experience, and enormous development cost. An assessment of the state-of-the-art of various advanced rotor systems, including past, present and future developmental plans and analysis techniques, are presented. Further, the applications of structural optimization and smart structures technology to the rotor system are discussed in order to reduce vibration, increase aeromechanical stability, minimize blade stresses and improve basic performance.

Rotor aeroelastic analyses in forward flight normally consist of calculating vehicle trim, steady response and stability of perturbation motion. Trim involves the calculation of control positions and vehicle orientation for a prescribed flight condition. Typically, there are two types of trim, free-flight and wind-tunnel trim. 
The former simulates the free-flight propulsive condition, and the latter simulates the test conditions in the wind tunnel. Steady blade response involves the calculation of blade deflections around the azimuth for one complete revolution. Using trim controls, steady response is calculated from nonlinear blade equations containing periodic terms as a forced response problem, using either the harmonic balance method, a time integration technique, or a finite element in time approach. For stability solutions, the perturbation equations of motion are linearized about the steady response and solved for stability roots. The rotor-body linearized equations are typically transformed into a fixed reference frame (body frame). These contain periodic terms in forward flight and are solved for roots using either Floquet transition matrix theory or constant coefficient approximation. All these phases of analysis are inherently coupled; however to simplify the analyses, these are generally uncoupled and solved individually. Then, coupling between different analyses is achieved through an iterative process. Invariably all analyses assume that all blades are identical and exposed to an identical environment (tracked condition). Chopra (1990) discusses the state of art of different analysis schemes to solve rotor dynamics problems. With new rotor systems, different phases of analyses need to be reformulated or modified and these are discussed in this paper.

\section{Hingeless and bearingless rotors}

Current rotor designs tend towards hinge- and bearingless rotors because of reduced costs and maintenance (fewer parts), better hub design (simple and clean aerodynamically), and superior handing qualities. In a hingeless rotor, flap and lag hinges are eliminated, and the pitch bearing is eliminated as well in a bearingless rotor. Such rotors are now becoming feasible because of the emergence of composite technology. Because these rotors are stiffer than articulated rotors, they are exposed to higher dynamic stresses. Due to stress and weight considerations, hingeless and bearingless rotors are designed as soft-inplane rotors which make them susceptible to aeromechanical instability. Articulated rotors are protected from ground resonance instability by mechanical lag dampers. However, the effectiveness of mechanical lag dampers is reduced for hingeless and bearingless rotors because of small lag displacements near the root. Also, with bearingless rotors, there is a redundancy of load paths at the root and many of the currently available dynamic codes cannot handle this. The increased forward speed and maneuverability expected out of future helicopters further aggravates this problem. It is therefore a challenging task to achieve aeromechanical stability of hingeless and bearingless rotors.

The distinguishing feature of a bearingless rotor is a torsionally soft flexbeam located between the main blade and hub. Pitch control to the blade is applied through a torsionally stiff torque tube by rotating it with pitch links, which in turn twists the flexbeam (figure 1). Large deflections in the flexbeam, especially in torsion, result in nonlinear bending-torsion couplings. Unlike the analysis of hingeless and articulated rotors where axial deflection can be routinely eliminated, analysis of bearingless rotors becomes complicated because axial deflections are needed to determine leads in different beams. Also, since the blade pitch is determined iteratively by adjusting the position of pitch links, i.e., boundary conditions at the torque tube, the analysis of a bearingless rotor is quite involved, especially in forward flight. Early analyses adopted an "equivalent beam approach" where flexbeams and torque tube together 
(a)

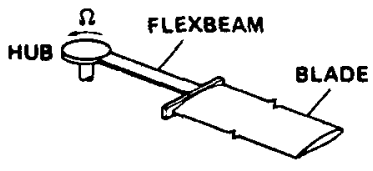

(b)

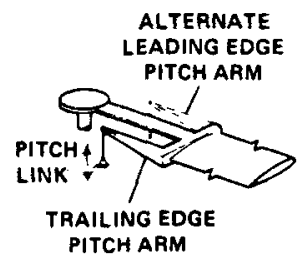

(c)

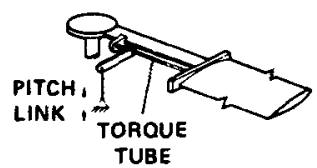

(d)

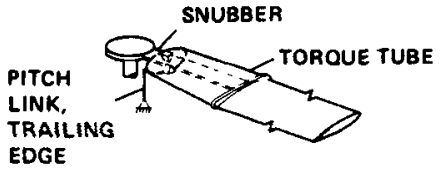

Figure 1. Principal configurations for bearingless rotor systems. (a) No pitch-control system; (b) cantilever pitch arm; (c) flexible torque tube; (d) torque tube and snubber.

were approximated as a single beam whose stiffness characteristics had to be calculated for each flight condition and then analysed using a hingeless rotor analysis. It was shown by Sivaneri \& Chopra (1984) that equivalent beam modelling cannot accurately simulate nonlinear structural couplings and can lead to erroneous stability results (figure 2). Finite element analysis appears natural to analyse bearingless rotors. It was applied the first time by Sivaneri \& Chopra (1984) to calculate the hover flap-lag stability of a simple bearingless configuration, and later on expanded (Dull \& Chopra 1988; Jang \& Chopra 1988; Jang \& Chopra 1989; Wang et al 1990), to analyse the aeromechanical stability of several bearingless configurations in hover and forward flight. Each of the flexbeams, torque tube and main blade are discretized into beam elements, and then certain displacement compatibility relations at the clevis (where flexbeams, torque tube and main blade join) are introduced into the assembled matrices. For hovering flight, the steady deflected position of the blade is calculated directly from nonlinear finite element equations using pitch links position as the boundary condition. The desired collective pitch is achieved iteratively by adjusting

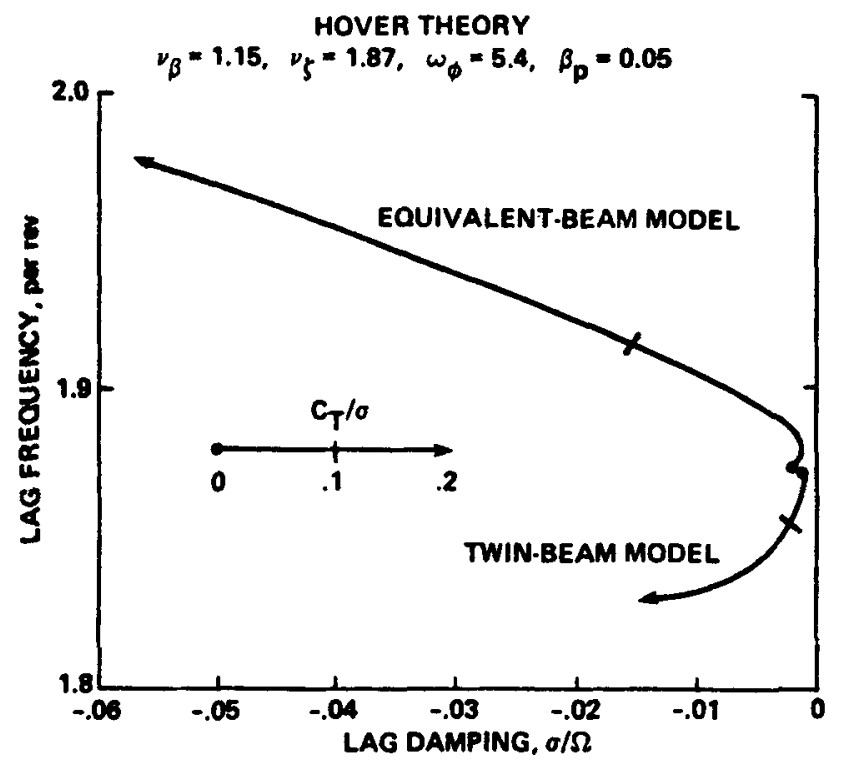

Figure 2. Bearingless rotor stability results (Shivaneri \& Chopra 1984). 


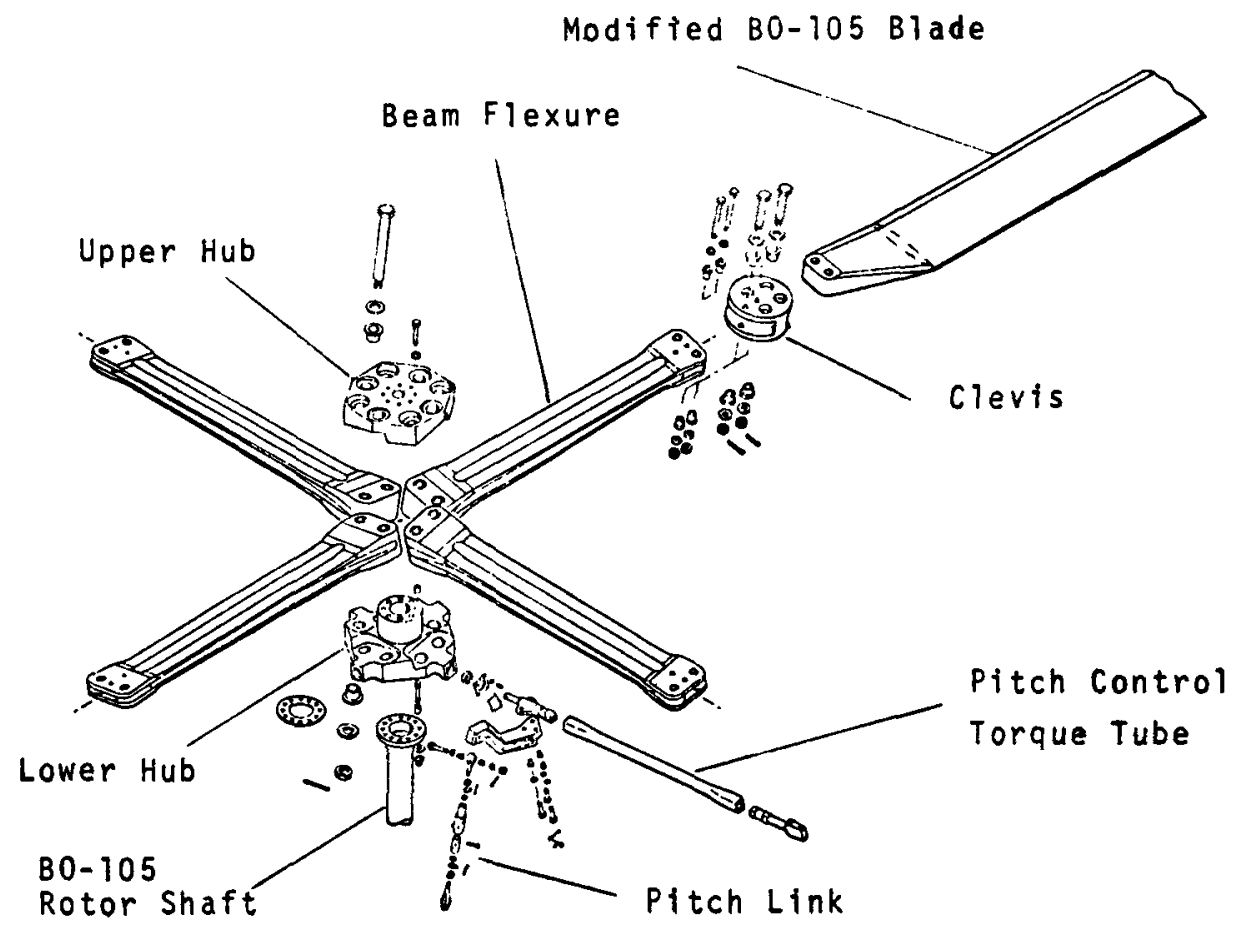

Figure 3. Boeing BO 105/BMR bearingless rotor system.

the pitch links position. In forward flight, the assembled finite element equations are nonlinear and periodic and also, the pitch link position varies along the azimuth. To reduce the computation time, these are first reduced to the modal space as a few (about six) normal mode equations. Then these are further discretized into nonlinear algebraic equations using finite-elements in time and solved iteratively. Other bearingless rotor analyses are discussed by Chopra (1990).

The Army's Aeroflightdynamics Directorate at Ames performed extensive aeromechanical stability testing in hover on hingeless and bearingless rotor models. These data form a part of the ITR data set (McNulty \& Bousman 1983) and are widely used by researchers to validate their analyses. Boeing built the first full-scale bearingless rotor (BO 105/BMR) and tested it successfully in the NASA Ames $40 \times 80 \mathrm{ft}$ wind tunnel. It consisted of twin flexbeams (C-beams) and a single torque tube rod and did not have lag dampers (figure 3). It was found to be marginally stable for many of the flight conditions. Also, it was flight tested successfully. Boeing, under the ITR program, also built a Froude-scaled four-bladed (diameter $6 \mathrm{ft}$ ) bearingless rotor (figure 4) which was extensively tested at Maryland's Glenn L Martin wind tunnel (Wang et al 1989; Wang \& Chopra 1990). It consists of a single flexbeam with a wrap-around torque tube with a vertical offset of the cuff snubber attachment point. The shear pin, in the form of a shaft-mounted spherical pivot, restrains the in-plane and out-of-plane motion of the cuff and introduces a negative pitch-lag coupling. This means that the lagwise shear reaction, coupled with vertical offset of the pivot from the elastic axis, produces feathering motion due to lag motion. Reducing pitchlink stiffness increases the effectiveness of the cuff-restraint and causes a stabilizing influence on air resonance stability (figures $5 \&$ 6). McDonnell Douglas and Bell respectively built HARP (figure 7) 


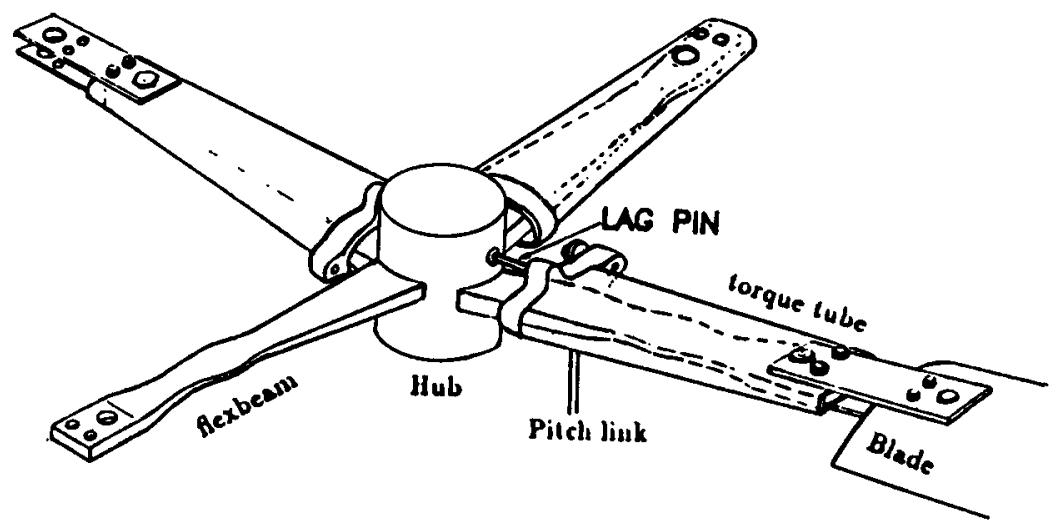

Figure 4. Boeing ITR bearingless rotor model.

and Model 680 (figure 8) full-scale bearingless rotors. In both these rotors, rotary type elastomeric lag dampers are installed between the torque tube and flexbeam. Also in the HARP rotor, the pitch link is slightly inclined to introduce negative pitch-lag coupling. There are several production bearingless tail rotors, such as on the Sikorsky Black Hawk (UH-60A) and S-76, MBB BO 105 and BK 117, and McDonnell Douglas Apache (AH-64A).

A key element in the design of a bearingless rotor is the flexbeam. To reduce hub drag and weight, it needs to be light and compact. The flexbeam undergoes large elastic deflections, say $\pm 5^{\circ}$ of flap deflection and $\pm 15^{\circ}$ of twist. Therefore, the flexbeam is designed for centrifugal force and large elastic deflections (bending stresses). It is necessary for the blade lag frequency to be as high as possible, but a lag frequency greater than $0.7 / \mathrm{rev}$ will lead to high dynamic stresses. The cross-section of the flexbeam is tailored along its length such that the flapping flexure (virtual hinge) falls inboard of lag and torsion flexure. It is now well established that soft-inplane hingeless and bearingless rotors are susceptible to air resonance instability, becoming worse at high thrust levels and Lock numbers (Chen \& Chopra 1991, figures 9a and 9b). To stabilize the rotor-body system, it is necessary to include elastomeric lag dampers and/or negative pitch-lag coupling. The characteristics of elastomeric dampers are

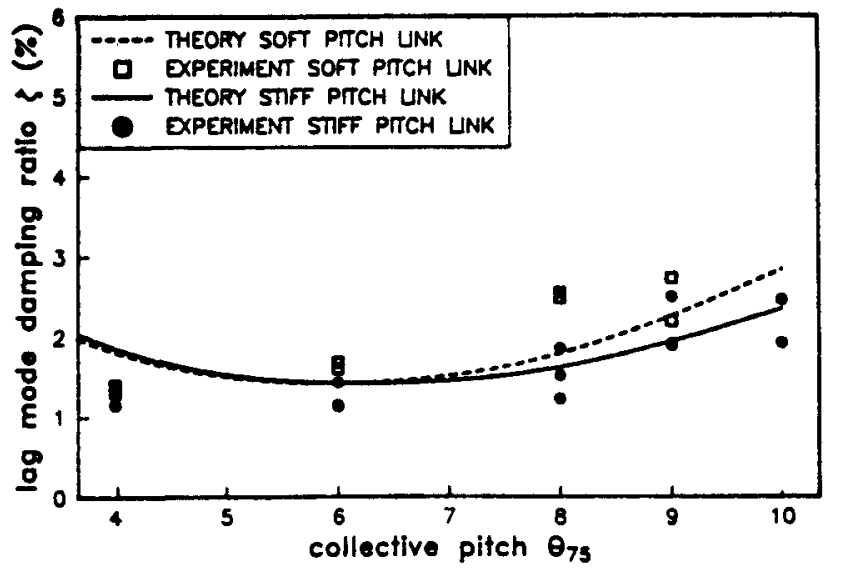

Figure 5. Aeromechanical stability ITR/BMR, $v_{\beta}=1 \cdot 1 / \mathrm{rev}$, $v_{\zeta}=0.7 / \mathrm{rev}$. Lag mode stability at $\mu=0.35$, forward shaft tilt $=4^{\circ} \quad$ (Wang \& Chopra 1990). 


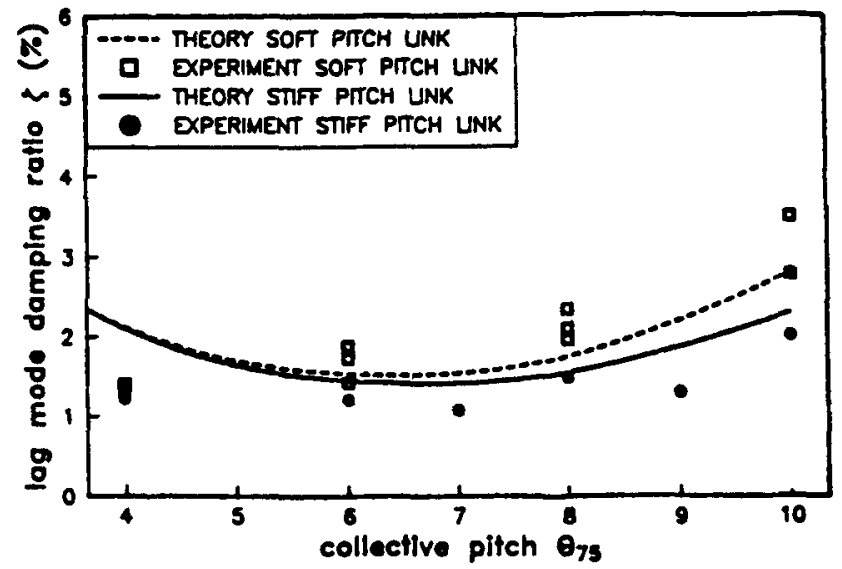

Figure 6. Lag mode stability at $\mu=0.35$, forward shaft tilt $=8^{\circ} \quad$ (Wang $\&$ Chopra 1990).

highly nonlinear functions of lag displacement and velocity and contribute to both stiffness and damping of lag mode. As shown in Chen \& Chopra (1991), unless the nonlinear characteristics of elastomeric dampers are modelled properly, it can lead to non-conservative results (figure 10). As far as pitch-lag coupling is concerned, one has to be careful, a negative value stabilizes air resonance stability but destabilizes ground resonance stability. There is no doubt that most of the future rotors will be built as bearingless rotors. As an example, the US Army's RAH-66 Comanche helicopter will incorporate a bearingless rotor. It is expected that more data will be available in future on loads, stability and response of bearingless rotor, which will help in validation of analyses and in our understanding of these systems.

\section{Composite rotors}

Advanced composites are poised for a quantum leap in the rotorcraft industry because of their superior fatigue characteristics as compared to metals, their higher stiffness-

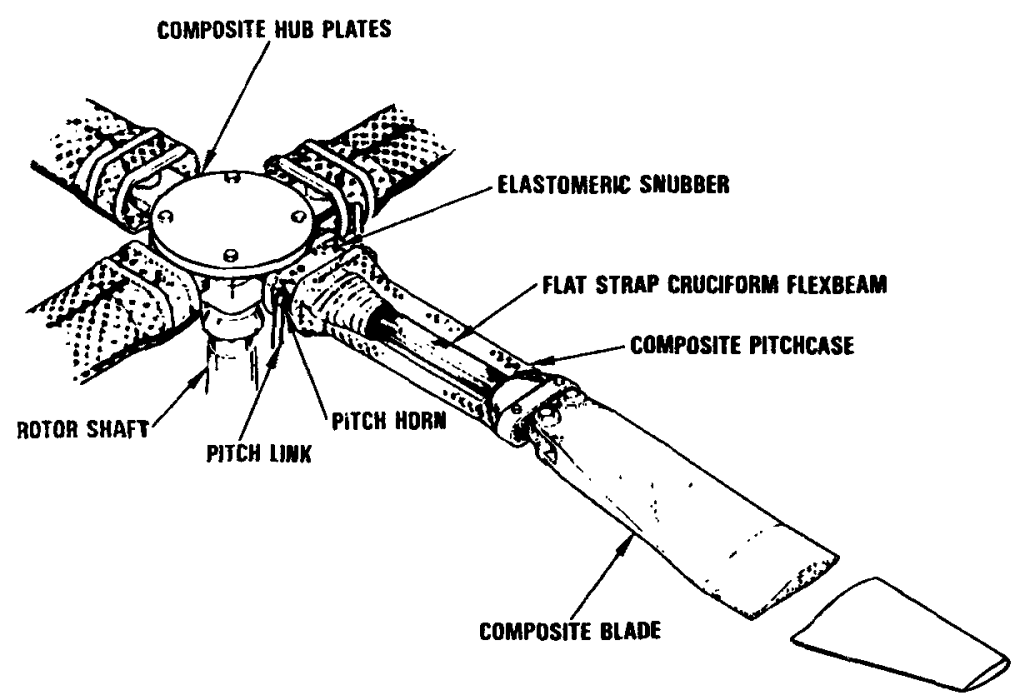

Figure 7. McDonnell Douglas HARP bearingless rotor. 


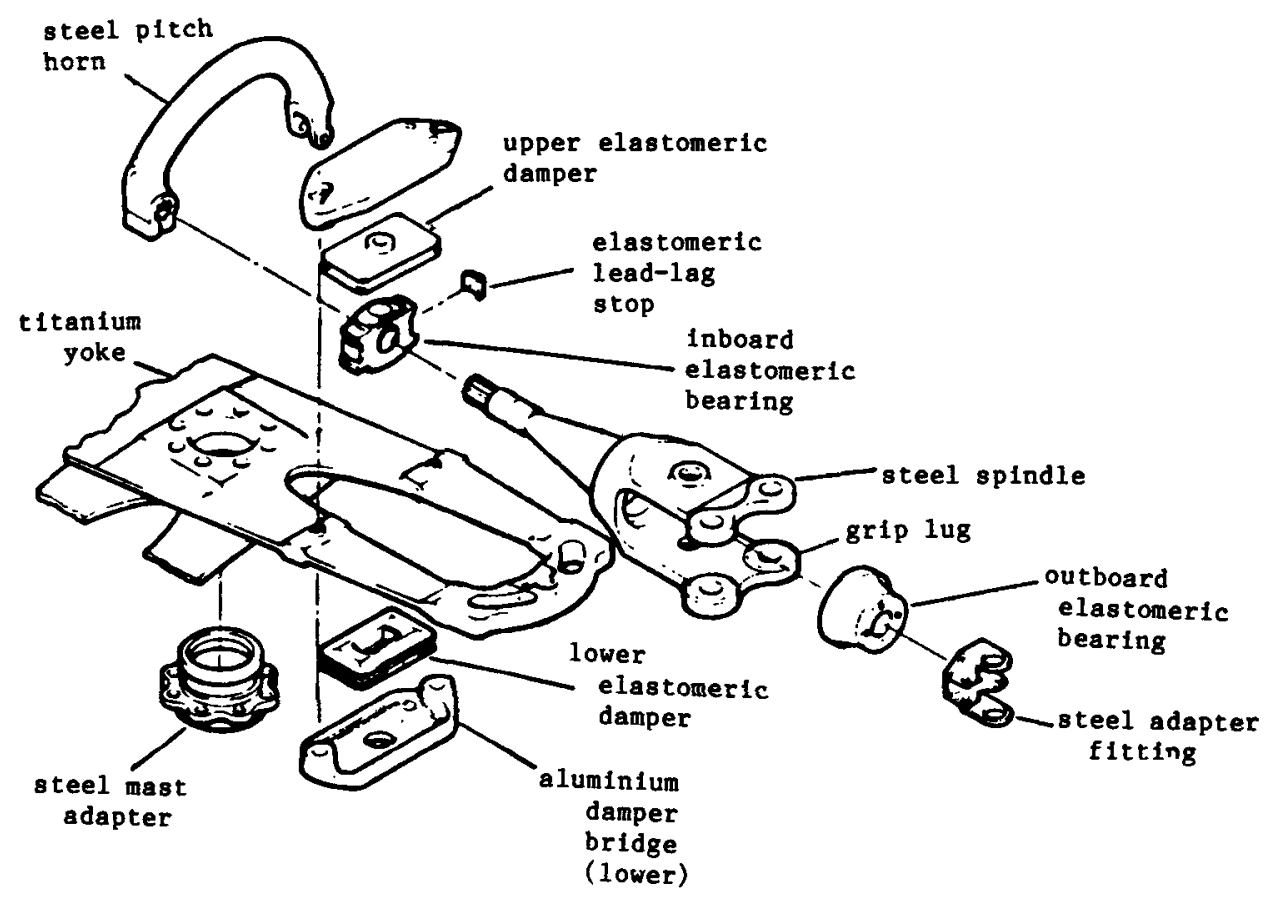

Figure 8. Bell Model 680 rotor hub configuration.

to-weight properties, their flexibility in tailoring structural characteristics, and their potential to lower production and operating costs. The rotorcraft industry is moving vigorously to apply composite technology to the construction of rotor systems and airframe structures. For example, the Army's ACAP systems, McDonnell Douglas's HARP bearingless rotor, Bell's Model 680 bearingless rotor, Boeing's Model 500 airframe, and Sikorsky's X-Wing were built extensively out of advanced composites.

There are also many concerns about composites, including lack of understanding of the structural couplings, failure mechanisms, and susceptibility to moisture and lightning strikes. At this time, an extreme level of conservatism is used in rotor designs with composites and thus the potential benefits of their structural couplings are not exploited fully. It is now becoming clear that for modelling of composite blades, nonclassical effects such as section warping, transverse shear and in-plane elasticity become quite important and need to be introduced in the analysis. With the availability of reliable analysis tools for a composite blade, it will be possible to tailor structural properties of the blade to reduce vibration, improve performance and increase aeromechanical stability. The state of art on analysis of a composite blade with a general ply layup is not available at this time.

An important load carrying member of the blade, i.e., spar, is generally a thin-walled closed-section tube (figure 11). Therefore, much can be learned about the behaviour of a composite blade from the analysis of a thin-walled single-cell slender beam. Accordingly, many formulations have been developed recently to model thin-walled composite beams. These range from simple analytical models (Hodges et al 1989; Minguet \& Dugundji 1990; Rehfield et al 1990; Smith \& Chopra 1991) to detailed finite elements models (Bauchau \& Hong 1988; Stemple \& Lee 1988; Kosmatka \& Friedmann 1989). Also, there have been some selected validations for these models 

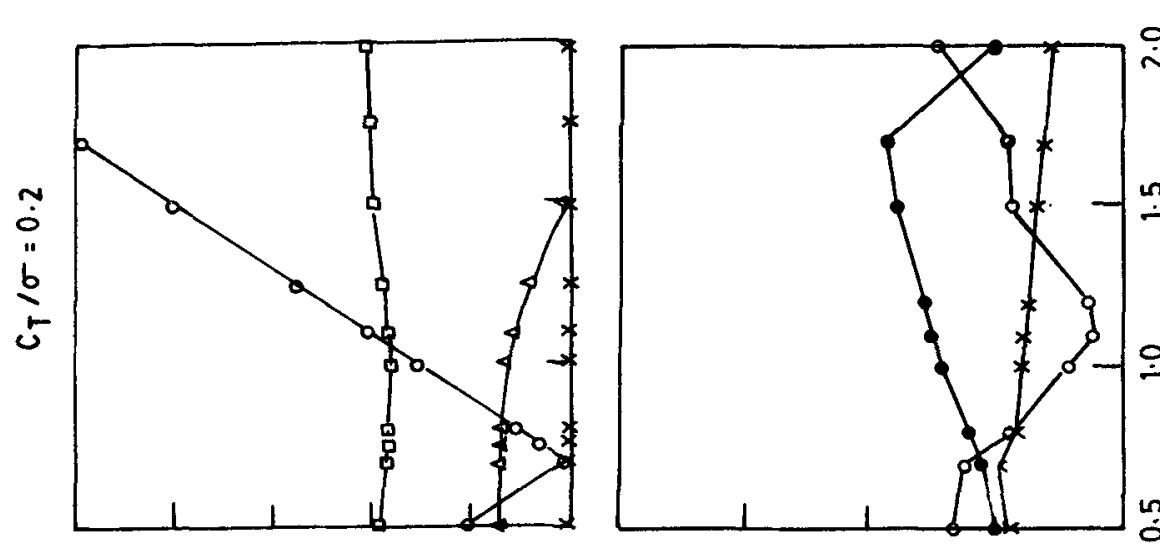

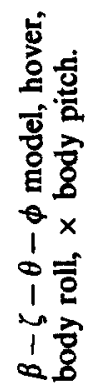

द

द

$\dot{0}$

递密
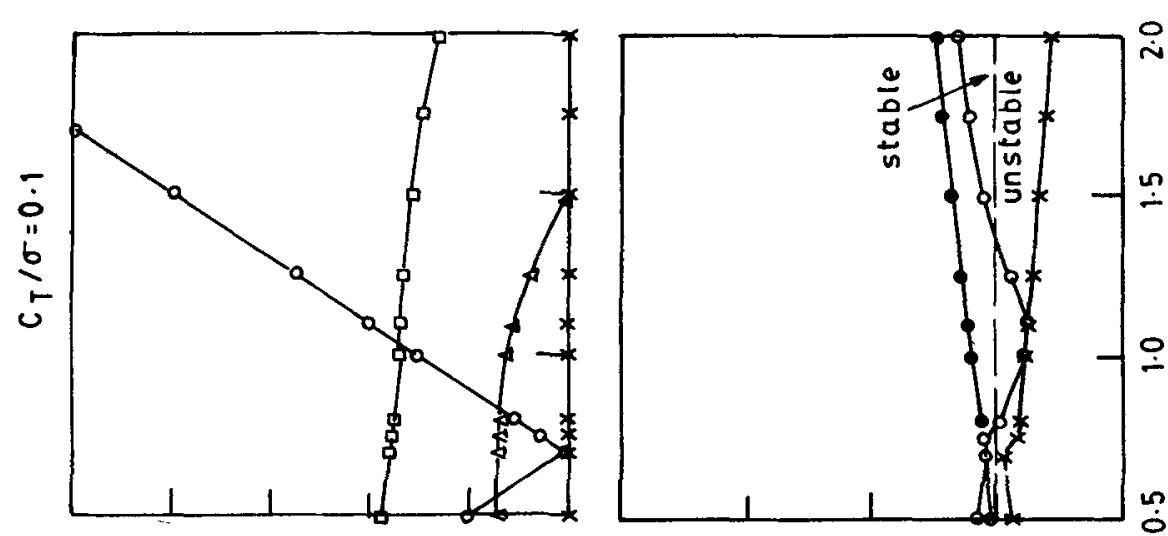

-

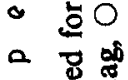

u 悹

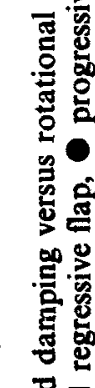
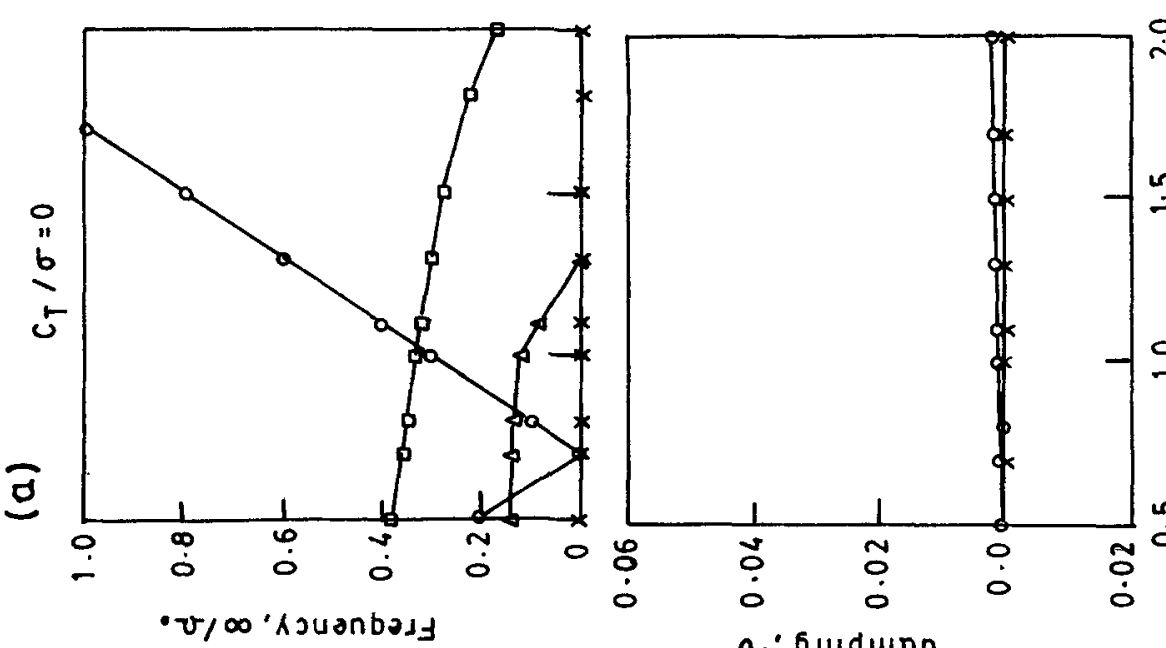

o- Gu!dudp

름

- ठ己영

蛋

必

ब品

可

홀

递

实文

å

影

量 

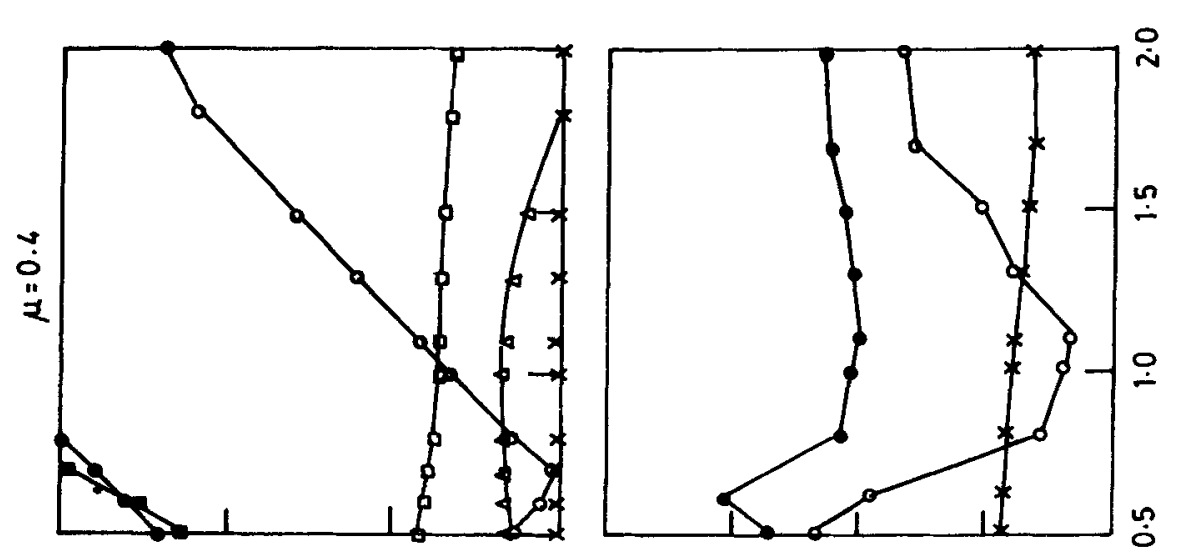

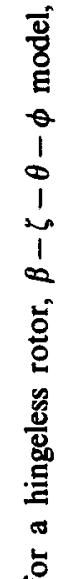
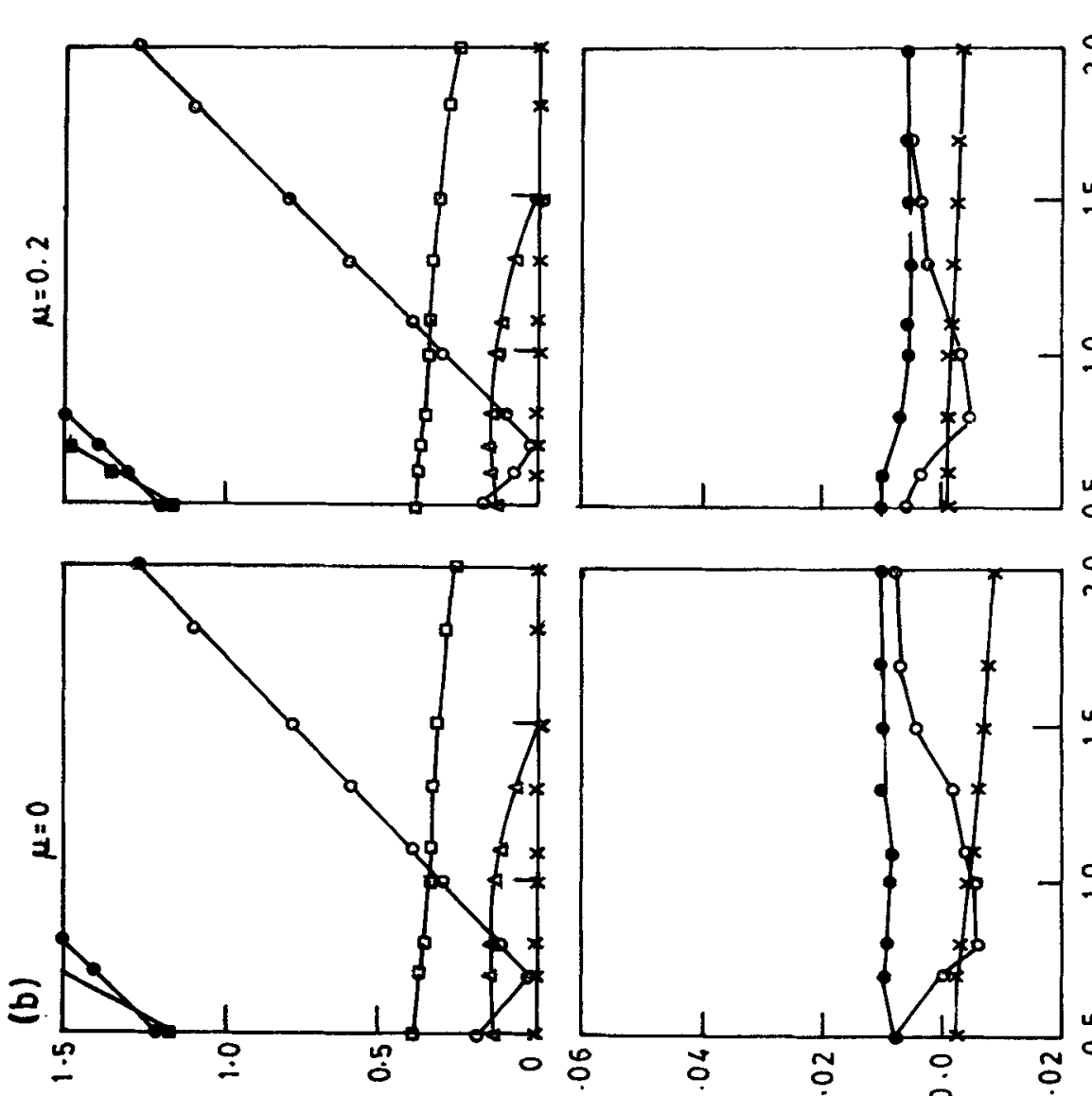

- $v / \infty$ isuanbast

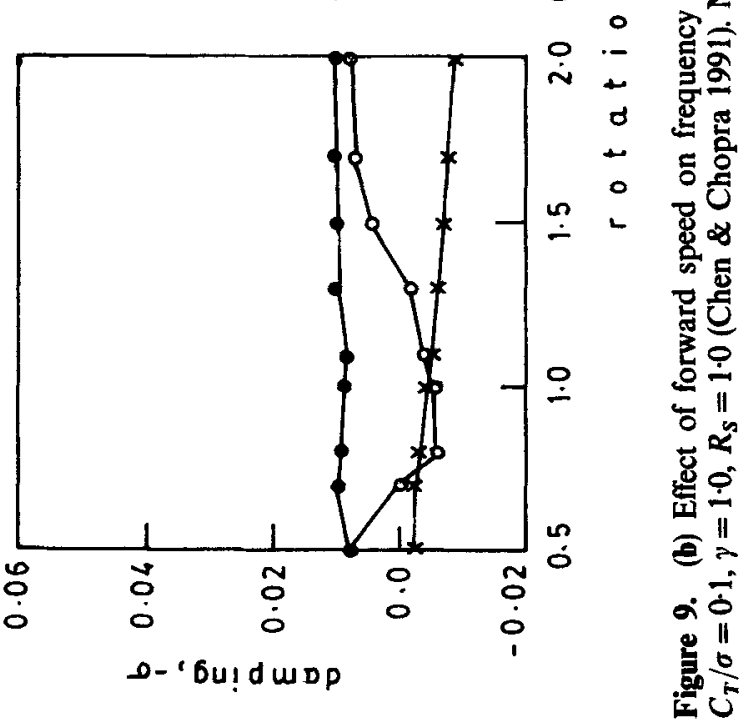



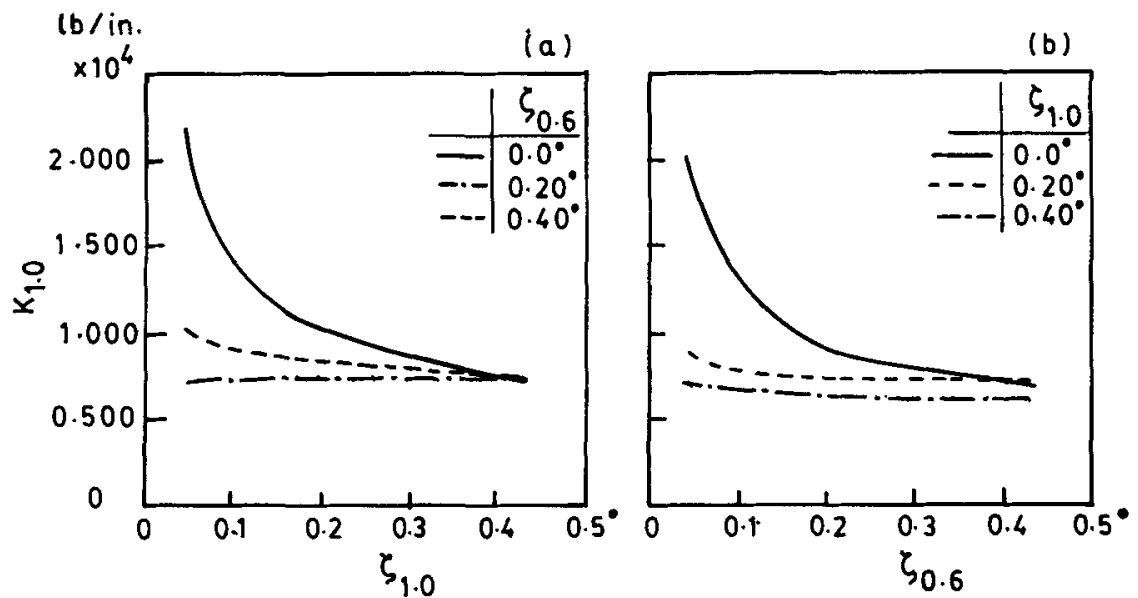

(c)

(d)
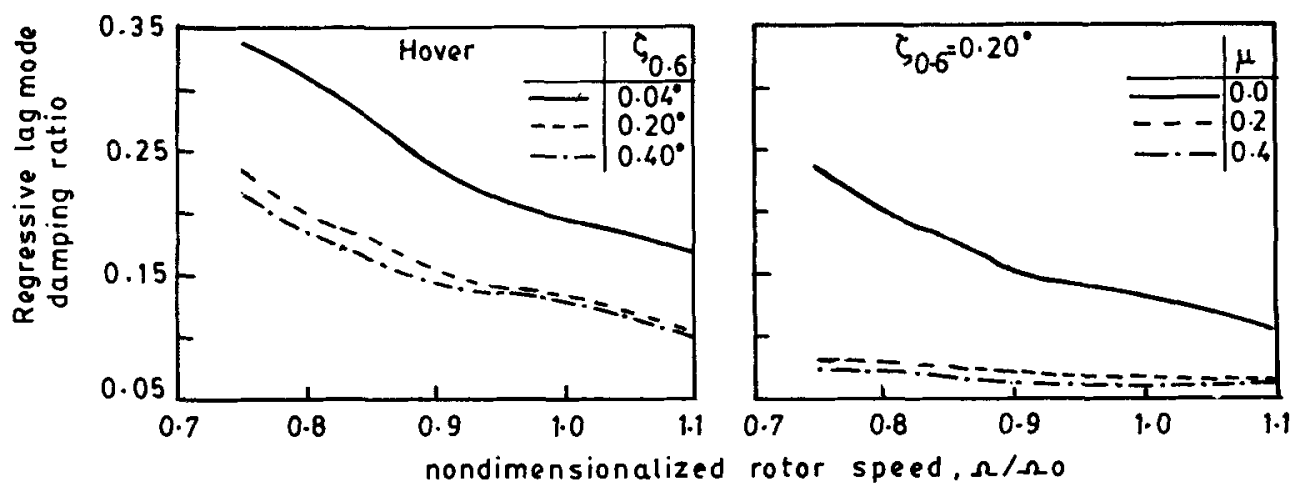

Figure 10. Variation of elastomeric stiffness with $1 / \mathrm{rev}$ (a) and $0.6 / \mathrm{rev}$ (b) lag amplitude (Bir \& Chopra 1981). Damping of the regressive lag mode as a function (c) of $0.6 / \mathrm{rev}$ lag motion amplitude $\left(\mu=0, C_{T}=0.08\right.$ ), and (d) of advance ratio $\left(C_{T}=0.08, \zeta=0.20^{\circ}\right)($ Bir \& Chopra 1981).

for static and vibration characteristics (Nixon 1989; Chandra et al 1990; Chandra \& Chopra 1992a).

For convenience, composite beams are categorized into symmetric and antisymmetric configurations based on their ply layups. In a symmetric configuration, the ply layups on opposite flanges are identical (mirror image) with respect to the beam axis whereas in an antisymmetric configuration, the ply layups on opposite flanges are of reversed orientation (figure 12). Following the simple linear analysis of Smith \& Chopra (1991) for bending and torsion of thin-walled symmetric composite beams:

$$
\left\{\begin{array}{l}
M_{f} \\
M_{c} \\
T
\end{array}\right\}=\left[\begin{array}{lll}
E I_{f} & 0 & K_{P_{s}}^{f} \\
0 & E I_{c} & K_{P_{z}}^{c} \\
K_{P_{s}}^{f} & K_{P_{s}}^{c} & G J
\end{array}\right]\left\{\begin{array}{c}
w^{\prime \prime}-\gamma_{x y}^{\prime} \\
v^{\prime \prime}-\gamma_{x z}^{\prime} \\
\phi^{\prime}
\end{array}\right\},
$$




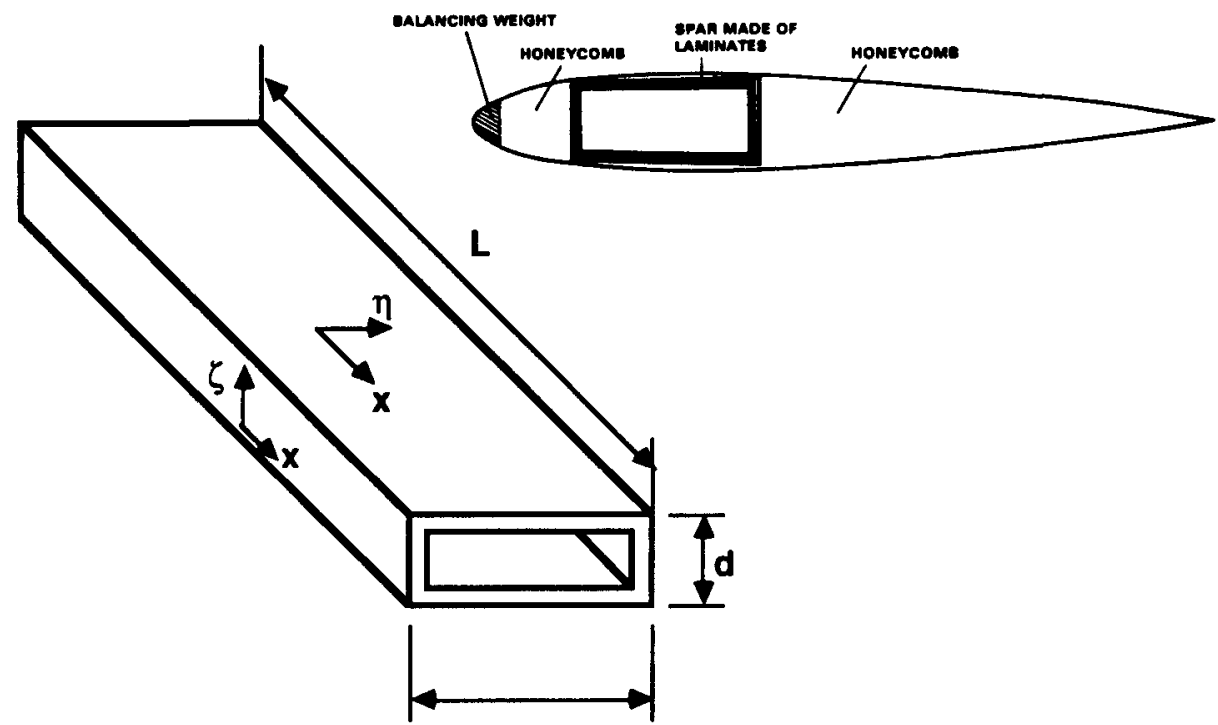

Figure 11. Composite blade section.

where $M_{f}, M_{c}$ and $T$ are respectively flap bending, chordwise bending and torque at a given station, and $E I_{f}, E I_{c}$, and $G J$ are respectively effective flap stiffness, chordwise stiffness, and torsional stiffness, and $w^{\prime \prime}$ is the flap bending curvature, $v^{\prime \prime}$ is the chordwise bending curvature, $\phi^{\prime}$ is the twist derivative, and $\gamma_{x y}^{\prime}$ and $\gamma_{x y}^{\prime}$ are derivatives of cross-section transverse shear strains. This symmetric layup configuration displays bending-torsion coupling and extension-shear coupling. The quantity $K_{P_{s}}^{f}$ is the flap bending-twisting structural coupling and is quite similar to the classical pitch-flap coupling. This coupling can be achieved through nonzero ply angles on top and bottom laminates. This coupling was seen to have a considerable effect on flap

Cross-Ply Layup Beam

- Alternating Plies at 0 and 90 deg

- No Elastic Couplings

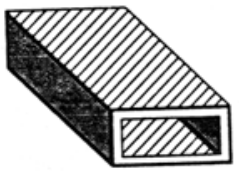

Symmetric Layup Beam

- Bending-Torsion Coupling

- Extension-Shear Coupling

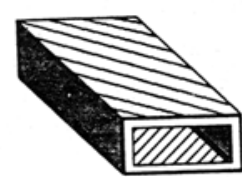

Anti-Symmetric Layup Beam

- Extension-Torsion Coupling

- Bending-Shear Coupling

Figure 12. Composite layup designation.

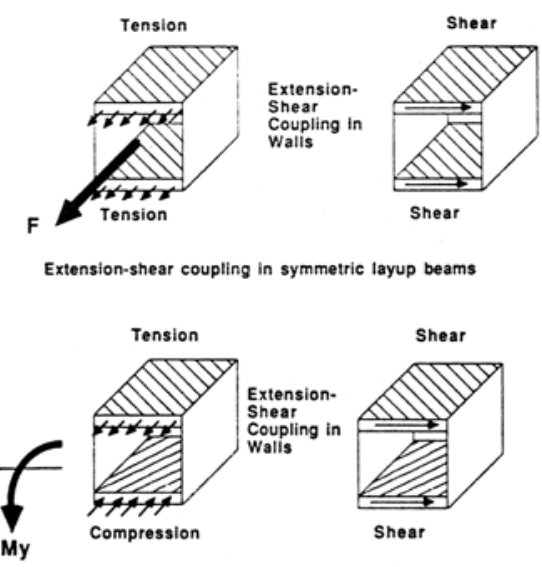

Bending-shear coupling in anti-symmotric layup beams 

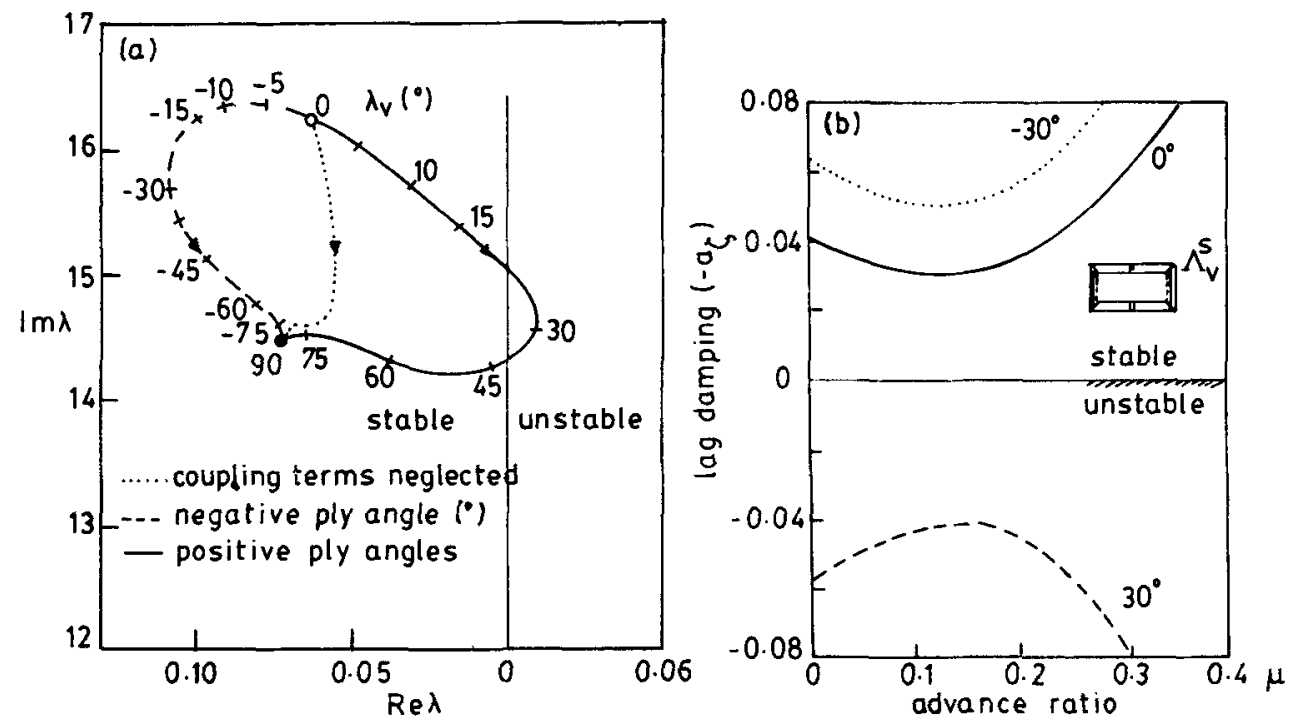

Figure 13. (a) Root locus for lag mode of a composite rotor (symmetric layup) in hover, $C_{T} / \sigma=0.1$ (Hong \& Chopra 1985). (b) Damping of low frequency lag mode of a composite rotor (symmetric layup), $C_{T} / \sigma=0.07$ (Panda \& Chopra 1987).

dynamics, and a greater effect on vibration and bending stresses than aeroelastic stability (Hong \& Chopra 1985; Nixon 1989; Minguet \& Dugundji 1990). The quantity $K_{p_{s}}^{c}$ is the chordwise bending-twisting coupling and is quite similar to classical pitch-lag coupling. This coupling can be achieved through nonzero ply angles on the side laminates or on the vertical web (I-beam). This coupling was seen to have a large effect on aeroelastic stability (Hong \& Chopra 1985, 1986; Panda \& Chopra 1987) (figure 13).

In a similar way, following the analysis of Smith \& Chopra (1991) a simple linear analysis for extension and torsion of thin-walled antisymmetric composite beams is derived as

$$
\left\{\begin{array}{c}
T \\
F
\end{array}\right\}=\left[\begin{array}{cc}
G J & K_{P_{a}} \\
K_{P_{a}} & E A
\end{array}\right]\left\{\begin{array}{l}
\phi^{\prime} \\
u^{\prime}
\end{array}\right\},
$$

where $F$ is the axial force, $E A$ is the effective extensional stiffness, and $u^{\prime}$ is the axial deflection derivative. $K_{P a}$ is the extension-twisting structural coupling and is caused by the nonzero ply angles on top and bottom laminates or side laminates. This coupling was seen to have a considerable influence on blade dynamics, including lag mode stability (Hong \& Chopra 1985, 1986; Panda \& Chopra 1987) (figure 14).

Including effects of transverse shear, causes bending-shear coupling for this configuration (Smith \& Chopra 1991).

$$
\begin{aligned}
& \left\{\begin{array}{c}
M_{f} \\
Q_{y}
\end{array}\right\}=\left[\begin{array}{cc}
E I_{f} & K_{P_{y}}^{S} \\
K_{P_{y}}^{S} & G A_{y}
\end{array}\right]\left\{\begin{array}{c}
w^{\prime \prime}-\gamma_{x z}^{\prime} \\
\gamma_{x y}^{\prime}
\end{array}\right\} \\
& \left\{\begin{array}{c}
M_{c} \\
Q_{z}
\end{array}\right\}=\left[\begin{array}{cc}
E I_{c} & K_{P_{z}}^{S} \\
K_{P_{z}}^{S} & G A_{z}
\end{array}\right]\left\{\begin{array}{c}
v^{\prime \prime}-\gamma_{x y}^{\prime} \\
\gamma_{x z}^{\prime}
\end{array}\right\},
\end{aligned}
$$




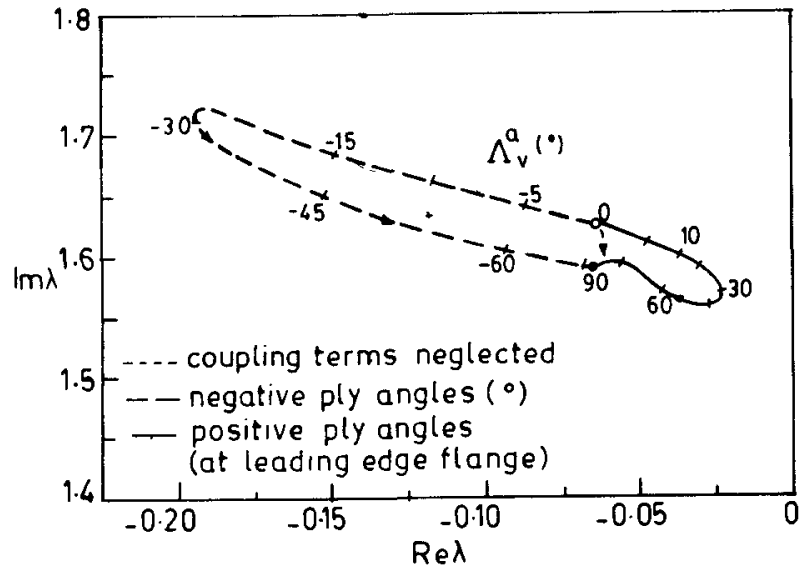

Figure 14. Roots locus for lag mode of a composite rotor (anti-symmetric layup) in hover, $C_{T} / \sigma=0.1$ (Hong \& Chopra 1985).

where $Q_{y}$ and $Q_{z}$ are net shear forces on the cross section, $G A_{y}$ and $G A_{z}$ are transverse shear stiffnesses and $K_{P_{y}}^{S}$ and $K_{P_{x}}^{S}$ are bending-shear couplings. It is interesting to note that for antisymmetric layup configurations, the extension and torsion of the beam are not elastically coupled to the bending and shearing of the beam.

The analysis of thin-walled closed-section slender composite beams showed that nonclassical effects, such as cross-sectional warping and transverse shear deflections, become important. An improved model for cross-sectional warping was developed (Smith \& Chopra 1991) which included the effect of variations in stiffness around the cross-section. As shown in figure 15, the effects of warping can become quite severe even for thin-walled composite beams. With the existence of elastic couplings, the effects of transverse shear can become quite significant even for slender beams. For symmetric layup configurations, extension and transverse shear are coupled, and for antisymmetric layup configurations, bending and transverse shear are coupled. Figure 16 shows considerable reduction of effective bending stiffness due to bendingshear coupling in an antisymmetric layup beam. Another important element of composite beam analysis is the adequate representation of two-dimensional in-plane

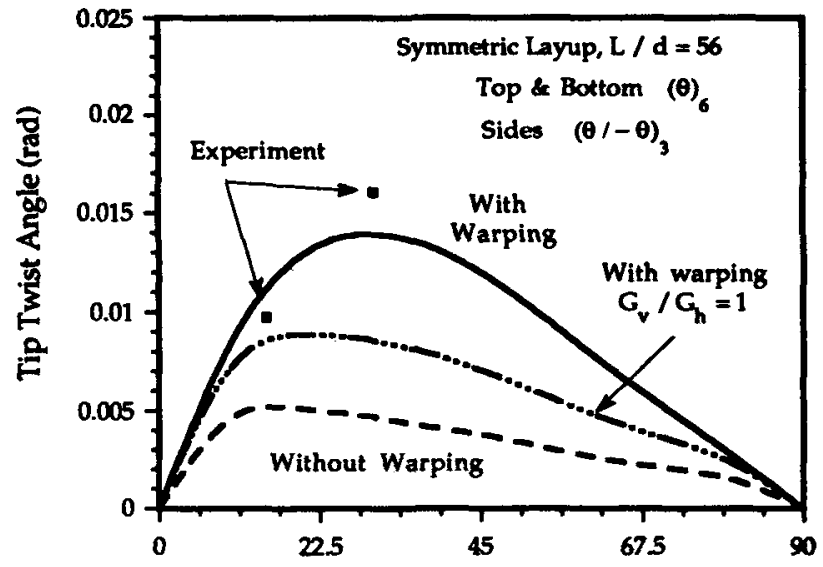

Ply Orientation Angle (degrees)
Figure 15. Tip twist under unit tip bending load for a symmetric layup thin-walled composite box beam, $L=30$ in., $d=0.537$ in., $C=0.953$ in. (Smith \& Chopra 1991). 


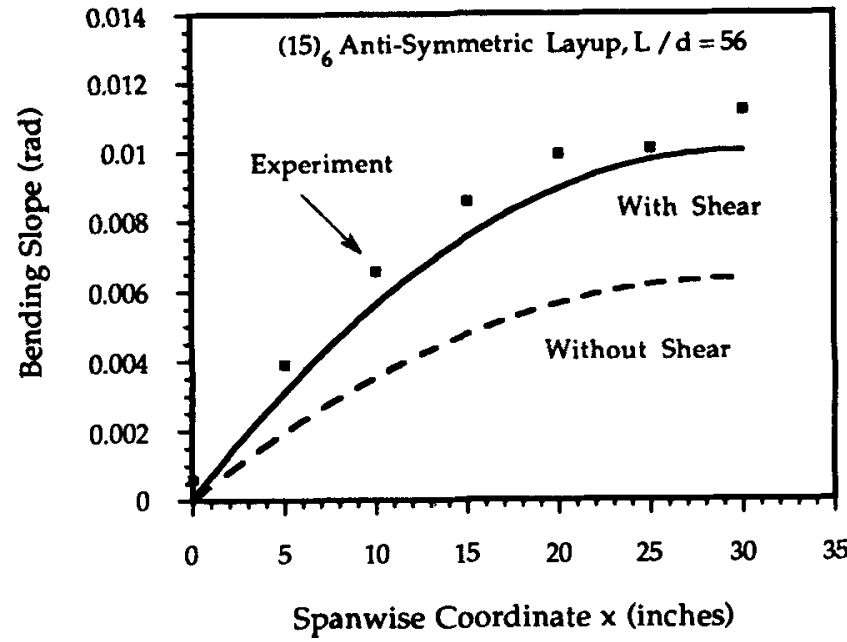

Figure 16. Bending slope under unit tip bending load for an antisymmetric layup thin-walled composite box beam, $L=30$ in., $d=0.537$ in., $C=0.953$ in. (Smith \& Chopra 1991).

elastic behaviour of plies. Smith \& Chopra (1991) consider three different formulations: classical beam theory (plane strain), plane stress condition and no in-plane forces and moments. The third approach shows better correlation with experimental data.

There have been some attempts to verify these structural couplings experimentally. In Chandra et al (1990), thin-walled rectangular section beams were built out of graphite/epoxy pre-impregnated tape using an autoclave molding technique and under bending, torsion and extensional loads. Uniform symmetric and antisymmetric layup beams were built for several cases. Measured bending slope and twist distributions were correlated satisfactorily (Chandra et al 1990; Smith \& Chopra 1991). These beams were also tested for their rotating vibration characteristics in the 10-foot diameter vacuum chamber (Chandra \& Chopra 1992a). Measured frequencies and mode shapes correlated satisfactorily with analytical predictions. At this time, there is better understanding of thin-walled closed section slender composite beams under static and dynamic loads than of open-section composite beams.

Open-section composite beams, such as I-beams, are used in the fabrication of flexbeams. Hong \& Chopra (1986) showed that bending-twist and extension-twist couplings introduced through ply orientations in I-beams influenced the dynamics of bearingless rotors substantially. The structural model used in that study was based on the solid section approach; constrained warping and transverse shear effects were not considered. Chandra \& Chopra (1991) developed a new formulation based on the Vlasov theory to analyse open-section composite beams. Each laminate (web or flange) is separately treated as a two-dimensional plate, and then using geometric considerations, two dimensional stress and displacement fields are related to one dimensional beam forces and moments. Effects of transverse shear were included. In order to validate this analysis, graphite/epoxy and kevlar/epoxy I-beams were fabricated and tested under bending and torsion loads. It was shown that the torsional stiffness of I-beams is significantly influenced by restraining the warping deformations (figure 17). About a $600 \%$ increase in torsional stiffness due to constrained warping is noticed for graphite/epoxy beams with a slenderness ratio of 30 . Using this new modelling, the calculated response of composite I-beams showed excellent correlation with measured data (figure 18). Rotating vibration characteristics of composite I-beams were determined experimentally in the vacuum chamber and correlated 


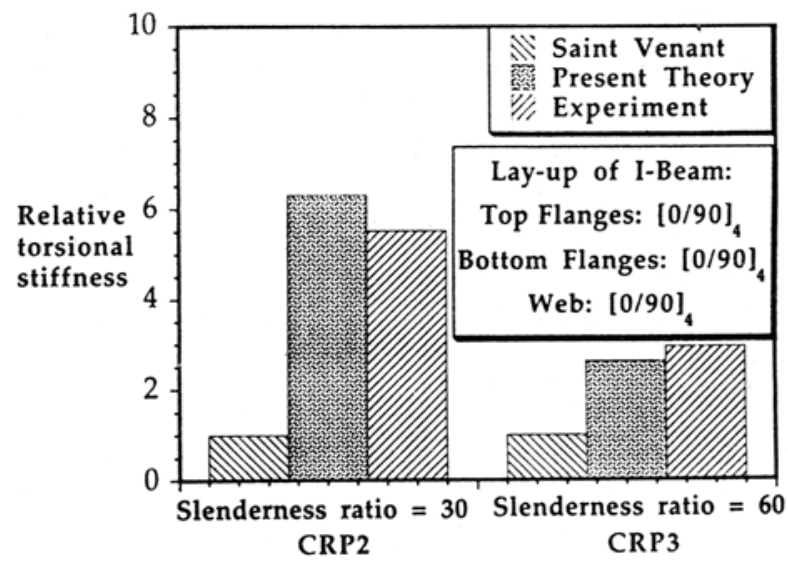

Figure 17. Torsional stiffness of a symmetric graphite-epoxy Ibeam under unit tip torsional load, length $=36$ in., width $=1$ in. (Chandra \& Chopra 1991).

successfully with analytical predictions (Chandra \& Chopra 1991b). Static and vibration characteristics of multi-cell elastically coupled composite blades were calculated using modified Vlasov theory and compared satisfactorily with measured data (Chandra \& Chopra 1992).

Recently, using improved composite beam modelling, comprehensive rotor aeroelastic analysis was reformulated and results were calculated for hub loads, blade response and aeromechanical stability for realistic rotor configurations (Smith \& Chopra 1992). A new nineteen degrees of freedom shear flexible element was developed for blade discretization. Again, this study showed that elastic couplings introduced through the composite blade spar have a powerful influence on both shaft-fixed blade stability and rotor-body stability.

By placing plies at specific layup and orientation, the desired structural couplings can be tailored. Therefore, there is great potential for composite tailoring of rotor blades to minimize blade stresses and vibration and to increase aeroelastic stability.

\section{Circulation control rotors}

A circulation control rotor utilizes circulation control (CC) airfoils. A CC airfoil typically consists of a quasi-elliptical profile with a thin jet of air blown from a spanwise slot near the trailing edge (figure 19). The jet remains attached at the rounded

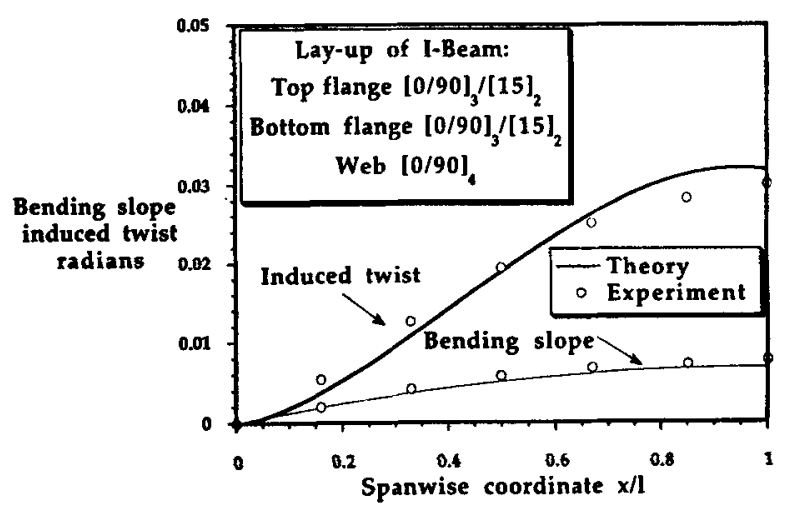

Figure 18. Variation of bending slope and induced twist in a symmetric graphite-epoxy I-beam under unit tip bending load, length $=36$ in., width $=1$ in., height $=1 / 2$ in., (Chandra \& Chopra 1991). 


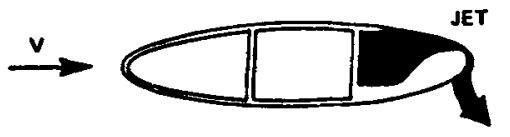

QUASI-ELLIPTIC

Figure 19. Typical circulation control airfoil.

trailing edge because of the balance of centrifugal force and the suction pressure - called the Coanda effect. At higher blowing, the stagnation point shifts towards the lower surface. With CC airfoils, lift can be controlled by jet momentum as well as by angle of incidence, and high lift coefficients of the order of 3 to 4 can be achieved. In a $\mathrm{CC}$ rotor, geometric pitch is held fixed and the cyclic control of lift is achieved through cyclic control of blowing (figure 20). A CC rotor allows a simplified hub design, high thrust at reduced tip speed, and easy implementation of higher harmonic control system. However, the Coanda principle works efficiently only for a limited range of blowing momentum and angle of attack. Also, there are serious concerns of CC technology on rotor dynamics.

The lift on a CC airfoil can be hypothesized into two components: lift due to blowing and lift due to angle of attack. For the blowing-lift, the aerodynamic centre is located near half-chord, whereas for angle-of-attack lift, the aerodynamic centre is located near quarter-chord. Figures $21 \mathrm{a}$ and $\mathrm{b}$ present lift and moment coefficients for a typical CC airfoil.

The airfoil section lift per unit span is given as

$$
L=\frac{1}{2} \rho V^{2} c C_{l}\left(\alpha, C_{\mu}\right),
$$

where $C_{\mu}$ is the blowing coefficient and is defined as

$$
C_{\mu}=\dot{m} V_{j} / \frac{1}{2} \rho V^{2} c \text {. }
$$

The quantity $\dot{m} V_{j}$ is the jet momentum, $\frac{1}{2} \rho V^{2}$ is the dynamic pressure and $c$ is the chord. With a conventional airfoil, a perturbation of the blade in-plane velocity influences the lift through a change in dynamic pressure and angle-of-attack. With the circulation control airfoil, a perturbation of in-plane velocity has additional effects through the change in momentum coefficient.

$$
\begin{aligned}
\delta L & =\frac{1}{2} \rho V^{2} c\left(\frac{\partial C_{l}}{\partial \alpha} \delta \alpha+\frac{\partial C_{l}}{\partial C_{\mu}} \delta C_{\mu}+2 \frac{\partial C_{l}}{\partial V} \delta V\right) \\
& =\frac{1}{2} \rho V^{2} c\left[\frac{\partial C_{l}}{\partial \alpha} \delta \alpha+2\left(C_{l}-C_{\mu} \frac{\partial C_{l}}{\partial C_{\mu}}\right) \frac{\partial V}{V}\right]
\end{aligned}
$$

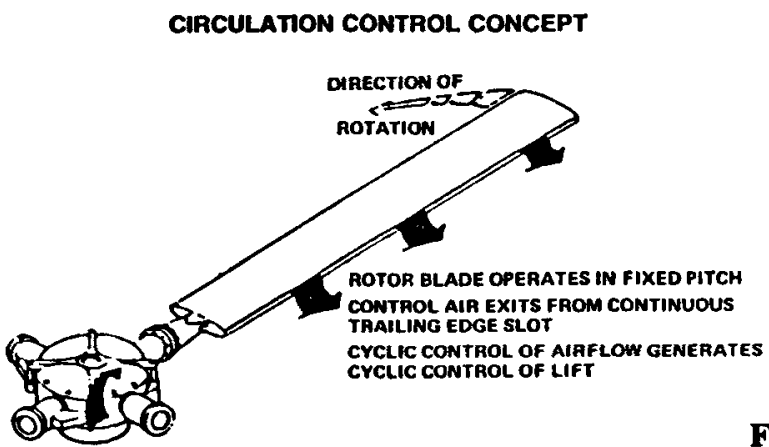

Figure 20. Circulation control rotor. 

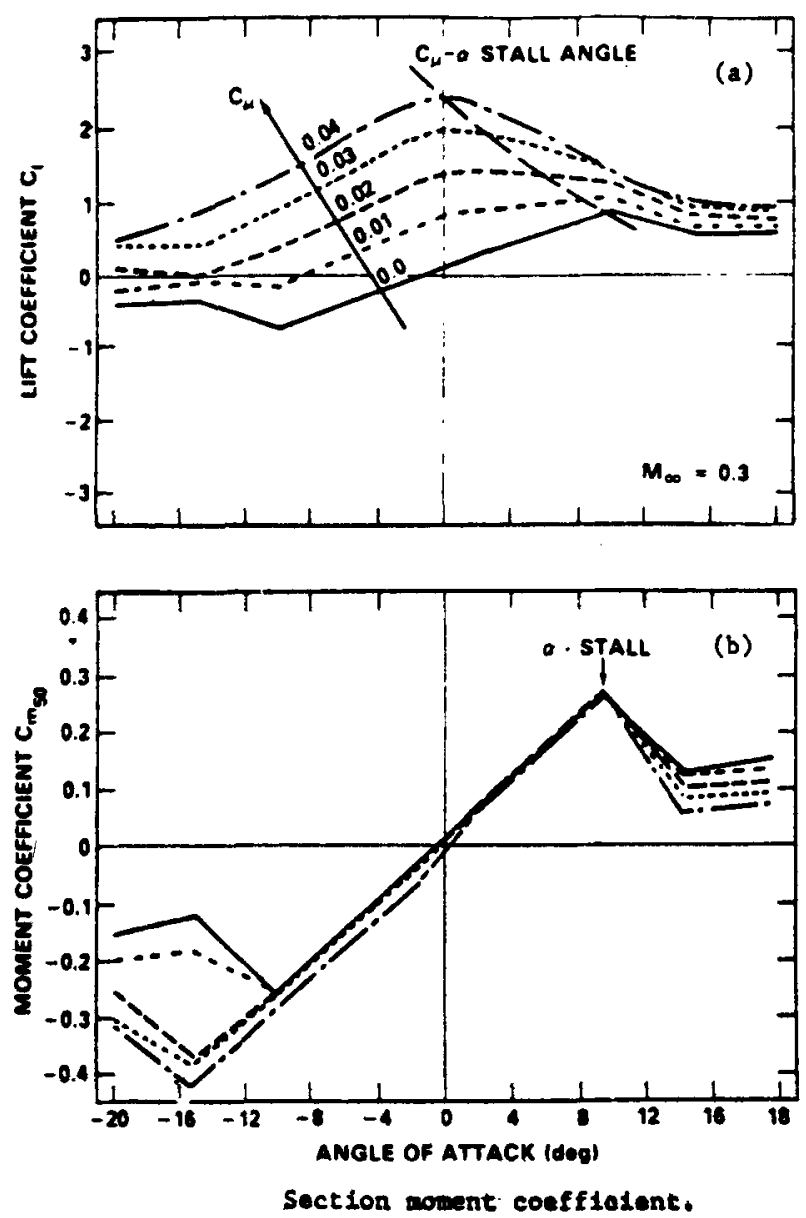

Figure 21. Lift and moment data for a typical CC airfoil: (a) Section lift coefficient and (b) section moment coefficient (Haas \& Chopra 1988).

It is assumed that the jet momentum is fixed.

$$
\delta C_{\mu}=\frac{\dot{m} V_{j}}{\frac{1}{2} \rho c}\left(-\frac{2 \delta V}{V^{3}}\right)=-2 C_{\mu} \frac{\delta V}{V} .
$$

Examining the perturbation of lift, a moderate amount of blowing will reduce the lift perturbation due to a perturbation in in-plane velocity, and a large amount of blowing will alter the sign of lift perturbation. This has considerable influence on blade stability.

Research on CC airfoils including their application to rotors was initiated by Cheeseman (1967) and later on vigorously carried on by David W. Taylor Naval R \& D Center over several years (Englar \& Applegate 1984). In addition to numerous scaledmodel tests in wind tunnels, full-scale rotary-wing and fixed-wing aircraft were also built using CC technology. Kaman built the first full-scale CC rotor, called XH2/CCR (Barnes et al 1979). It consisted of four blades with a diameter of $44 \mathrm{ft}(13.4 \mathrm{~m})$. It was tested successfully for many flight conditions in the Ames $40 \times 80$ foot wind tunnel, but the flight program could not proceed because of inadequate cyclic control during transition flight. Lockheed built the first fullscale stoppable rotor, called $\mathrm{X}$-wing 
(Reader et al 1976). It consisted of four blades with a rotor diameter of $25 \mathrm{ft}(7.6 \mathrm{~m})$. An X-Wing aircraft takes off like a helicopter, picks up sufficient forward speed and then the rotor is stopped and it continues flying as a fixed-wing airplane. During the landing flight sequence, the wings are set into rotation and the vehicle transforms into a helicopter. An X-Wing therefore provides the hover and low speed efficiency of a helicopter and the high speed cruise efficiency of a jet airplane. These capabilities are accomplished using dual slot $\mathrm{CC}$ airfoils (slots at both leading and trailing edge). Lockheed tested their rotor in the NASA Ames $40 \times 80 \mathrm{ft}$ wind tunnel and on the hover stand successfully, but did not attempt flight testing. Later on, Sikorsky built a larger version of the X-Wing for testing on the RSRA aircraft (flying test bed) (Linden \& Biggers 1985). It consisted of four blades with a rotor diameter of $56 \mathrm{ft}(17 \cdot 1 \mathrm{~m})$. Because of safety and many other concerns, it was not flight tested. There is no doubt that an X-Wing aircraft is a technology challenge at this time and requires numerous advances and innovations related to $\mathrm{CC}$ phenomenon. Blades of the $\mathrm{X}$-Wing are an order of magnitude stiffer than conventional helicopter blades (flap frequency $2 \cdot 1 / \mathrm{rev}$ for X-Wing versus $1 \cdot 1 / \mathrm{rev}$ for hingeless BO 105 rotor) and this aggravates many dynamics problems. To keep dynamic stresses within acceptable limits, the starting and stopping operations of the rotor must be accomplished quickly (say within $10 \mathrm{~s}$ ). This necessitates an active control of blowing momentum during the change-over phase from rotating blades to fixed-wings and vice versa. Since two of the wings are swept forward $\left(45^{\circ}\right)$, aeroelastic divergence can become an issue.

The high lift capability of CC airfoils was investigated to reduce take-off and landing distances of fixed-wind airplanes (STOL application) (Englar et al 1978). The Navy is developing a two-bladed stoppable rotor using CC technology for an unmanned aerial vehicle (UAV). Sikorsky examined the potential of $\mathrm{CC}$ technology to the application of higher harmonic control of helicopter vibration (Lorber \& Carson 1989). Since many harmonics can be incorporated (say up to the first 8 ), this can be used to actively control blade stresses and augment rotor stability. Circulation control technology has been used successfully on a helicopter tail boom to replace a conventional tail rotor as a means of reacting main rotor torque and providing directional control (NOTAR concept) (Logan 1982).

There are a few selected investigations on the aeroelastic stability of a CC rotor (for a recent review see Chopra 1990). A basic formulation was developed to examine the stability of a CC rotor in hover (Chopra \& Johnson 1979). A simple blade model consisting of three degree-of-freedom, flap, lag and feather rotations about hinges, was used, as were airfoil characteristics in the form of analytical expressions. It was shown that trailing edge blowing has substantial influence on blade stability. Contrary to the behaviour of hingeless rotors with conventional airfoils, strong flap-lag instability can occur in a CC rotor at low thrust levels provided blowing momentum is high. Unless some form of kinematic coupling (such as pitch-lag and pitch-flap coupling) is incorporated, structural damping alone may not suffice to correct this instability. Furthermore, because of the location of the elastic axis (spar position) at half-chord, there is a possibility of single-degree torsional instability, showing the need to augment blade torsional damping. From this analysis, it became certain that the $\mathrm{CC}$ rotor cannot be designed as soft-in-plane hingeless rotors because of strong aeroelastic instability. Johnson \& Chopra (1979) investigated the flight stability of $\mathrm{CC}$ rotors in hover using this simple three-degree blade model. Blowing caused a large reduction in the rotor-speed stability derivative. Above a certain blowing level, which depends on the flap frequency and rotor lift, negative speed 


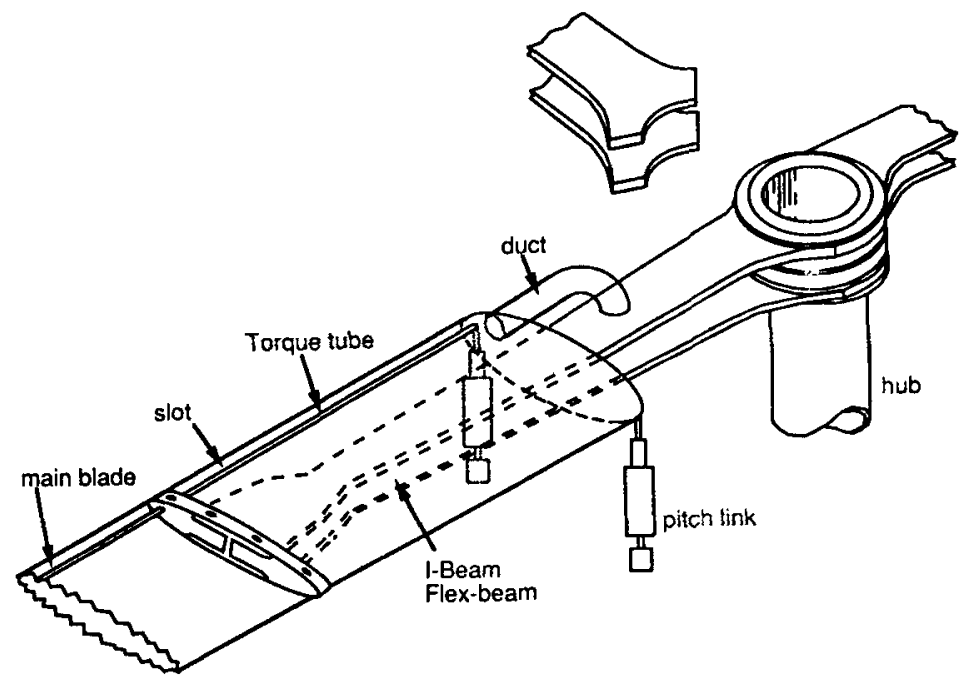

Figure 22. Bearingless circulation control rotor.

stability is caused and the dynamic characteristics of the rotor are totally changed. Again, it was shown that the blowing had a substantial influence on the flight dynamics of a helicopter.

The aeroelastic stability of an elastic rotor in hover was investigated (Chopra 1984, 1985) using the finite element formulation for hingeless and bearingless configurations. The airfoil characteristics were taken in the form of data tables. Again, it was shown that trailing edge blowing had an important influence on the aeroelastic stability of the rotor. Negative collective pitch (typically used) caused unstable effects on lag mode stability whereas positive pitch was stabilizing. The dynamics of a bearingless rotor (figure 22) in forward flight was examined (Chopra 1988). This configuration represented the characteristics of Sikorsky's X-Wing rotor. The effects of pneumodynamics and centrifugal pumping (Watkins et al 1985) in the pressure duct were included to determine the jet momentum at different stations. In forward flight, the flap response consisted primarily of $2 / \mathrm{rev}$ and its amplitude increased with higher speed, showing large bending stresses (figure 23). It is quite clear that some form of active feedback system is required to control blade bending stresses as well as helicopter vibration. Lag mode damping becomes more unstable at low forward speed as collective pitch is decreased (figure 23). Again, this points to the need to augment damping of lag mode either using elastomeric dampers or an active feedback system.

In the above mentioned aeroelastic analyses, quasisteady aerodynamics is used. Raghavan et al (1988) formulated a simple model for the unsteady boundary layer for a two-dimensional $\mathrm{CC}$ wing. Both unsteady freestream and unsteady blowing were considered. For an elliptic airfoil, an unsteady potential flow solution was calculated using conformal mapping, and the wake was modelled using distributed source panels in the separated region. Substantial unsteady effects were observed for thick airfoils at large blowing rates and large reduced frequencies. Recently, Ghee \& Leishman (1990) carried out a systematic experiment to determine the effects of unsteady blowing on the lift development of a two-dimensional wing. The results showed that there was significant increase of lift augmentation over and above the 

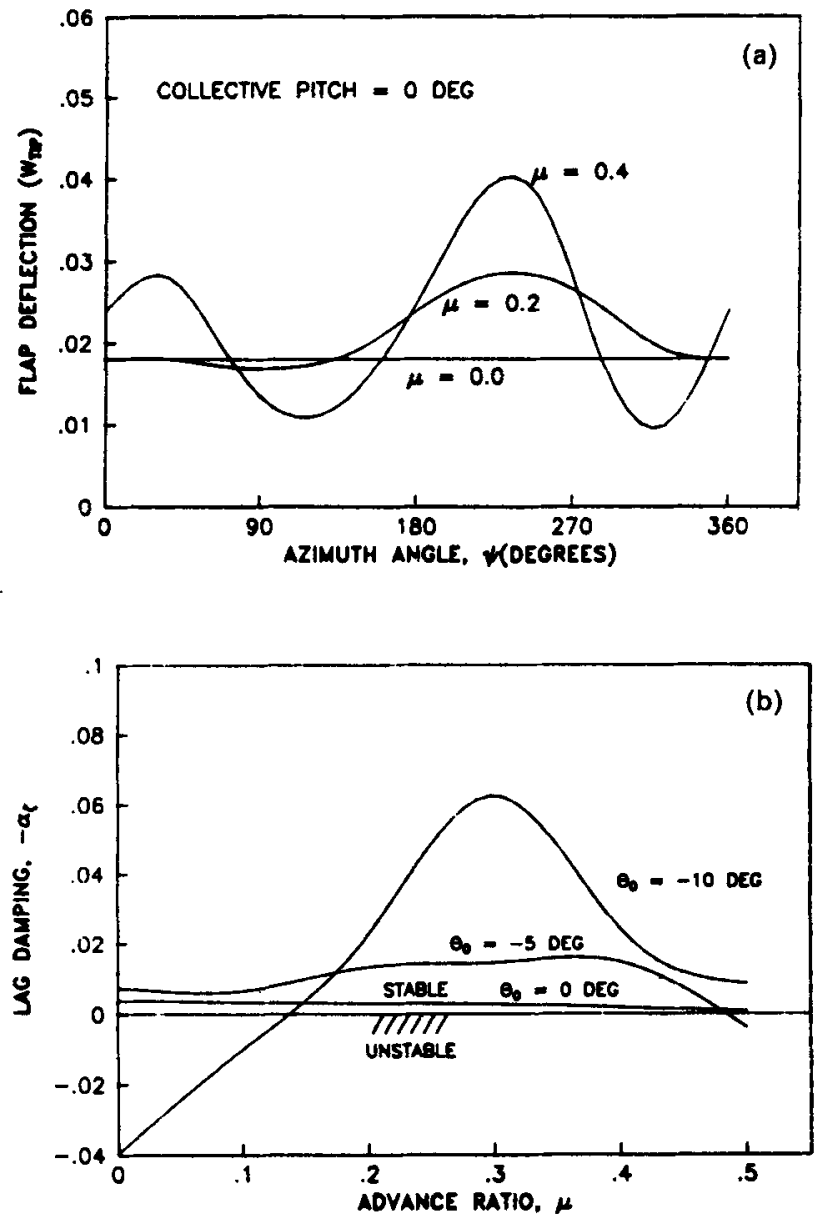

Figure 23. (a) Blade flap bending deflection at tip for a bearingless $\mathrm{CC}$ rotor $\left(C_{T} / \sigma=\right.$ $0 \cdot 1, v_{\beta}=2 \cdot 5 / \mathrm{rev}, v_{\zeta}=2 \cdot 3 / \mathrm{rev}$, $v_{\theta}=21 / \mathrm{rev}$ ) (Chopra 1988). (b) Effect of collective pitch on low frequency cyclic lag mode (Chopra 1988).

static values due to unsteady blowing. Again, unsteady effects appear important and must be considered for $\mathrm{CC}$ rotor analysis.

Haas \& Chopra $(1988,1989)$ showed that blowing has considerable influence on the static divergence and flutter of a CC fixed-wing airplane. It was shown that a loss of blowing control effectiveness occurs on an aft-swept $\mathrm{CC}$ wing and may lead to control reversal at high blowing levels. A flutter phenomenon unique to $\mathrm{CC}$ wing was discovered, and is referred as "CC flutter". It occurs at low angle of attack with high blowing. It is caused by blowing stall and results in an instability of the low frequency bending mode. This analysis helped to explain the limit-cycle instability that was observed in wind tunnel tests at the United Technology Research Center on the X-wing dynamic model at certain flight conditions. Further, it was shown that with high blowing, the aircraft short period mode also becomes unstable.

There is no doubt that trailing edge blowing has a powerful influence on the aeroelastic reponse and stability, flight mechanics and performance of fixed-wing as well as rotary-wing aircraft, and must be considered for design development of the system. 


\section{Tilt-rotors}

A tilt-rotor aircraft combines the vertical take-off and landing capability of a helicopter and the high-speed cruise capability of a turboprop aircraft (figure 24). The dynamics of a tilt-rotor is more involved than a conventional helicopter rotor because of coupling resulting from wing motion, tilting of the main rotors, high inflow ratio in axial flight, variable rotational speed, and highly twisted blades. In addition to the aeromechanical instabilities of conventional rotors, there are some unique instabilities such as the whirl flutter encountered in a tilt-rotor system. In spite of continuing full-scale development of tilt-rotor aircraft, there are still many concerns about its dynamics.

Over several years, many analytical and experimental studies have been conducted to provide insight into several aeroelastic and dynamic problems associated with a tilt-rotor aircraft. Kvaternik (1973) carried out a systematic proprotor/pylon whirl flutter instability in axial flight. Whirl flutter is caused by coupling of proprotor motion and support motion and occurs at a high forward speed. The analysis was developed for the system undergoing rigid flap motion for blades, three translational and three rotational degrees of motion for the pylon, and vertical bending motion for the wing. Systematic studies were carried out to examine the influence of several design parameters on whirl flutter instability. Calculated results were also correlated successfully with measured stability data obtained from a dynamically scaled semi-span wing/tilt-rotor model in the wind tunnel. The outgrowth of this study was the widely followed code, called PASTA. Johnson (1974) developed a theoretical model for a tilt-rotor on a cantilever wing in high inflow axial flight. The analysis involved first flap and lag bending modes for blades (six degrees for three-bladed rotor), and lowest frequency wing elastic bending (vertical and chordwise) and torsion modes. The pylon with a large mass and moment of inertia is rigidly attached at the tip of the wing. Several parametric studies were conducted to examine the sensitivity of the stability results to various elements in the theoretical model and different proprotor

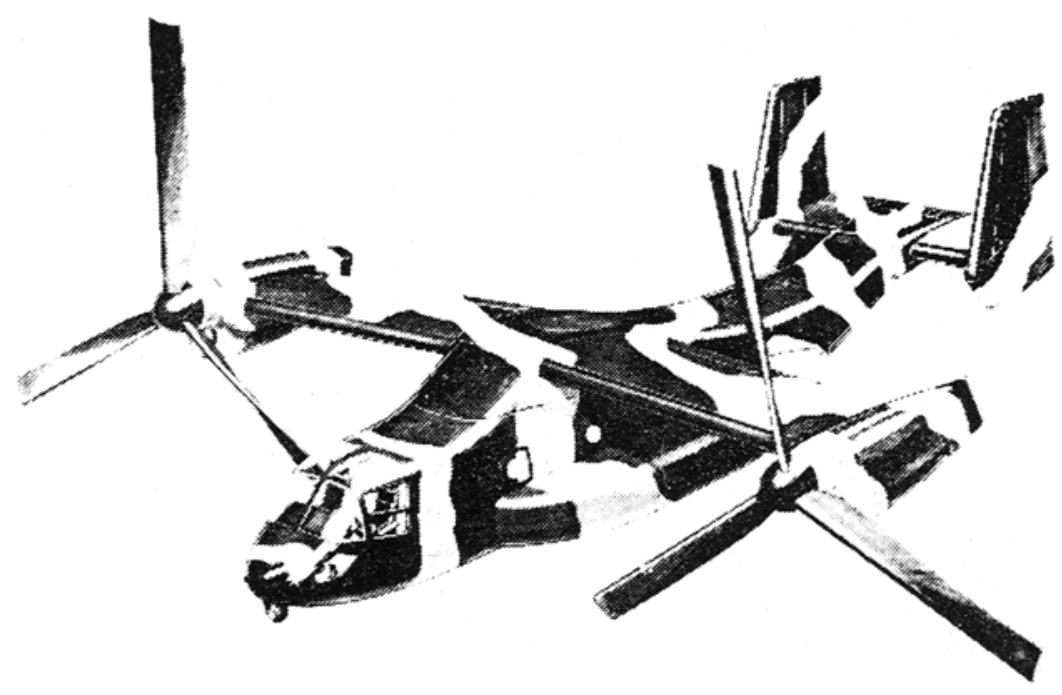

Figure 24. Tilt-rotor aircraft. 
configurations. Calculated stability results were correlated successfully with the test results of two full-scale proprotors in the NASA Ames 40 - by 80 -foot wind tunnel. This study showed the need to include the lag degree of freedom for hingeless proprotor designs. Later on, Johnson (1974b) extended the proprotor dynamic analysis to include elastic coupled rotor modes (flap, lag and torsion) and nonaxial flight. It covered a helicopter in forward flight and a conversion mode flight condition. From the application of the analysis to a gimballed rotor and a hingeless rotor (Johnson 1975), it was shown that for an accurate prediction of dynamic stability, it is important to include blade bending flexibility, a proper representation of root and hub configuration, precise modelling of the rotor support system (i.e. wing), and gimbal and rotor-speed degrees of freedom. These analyses were included in the widely-used code, CAMRAD (Comprehensive Analytical Model of Rotorcraft Aerodynamics and Dynamics) (Johnson 1980, 1981), where in addition to dynamic stability, performance and loads of tilting proprotor aircraft can be also calculated. Bell Helicopter (Popelka et al 1985) developed inhouse their own code, called DYN4, to predict the dynamics of a tilt-rotor aircraft. Johnson $(1984,1985)$ made an assessment of analytical capability for tilt-rotor aircraft in relation to the XV-15 tilt rotor research aircraft. For future methodology development, he recommended the improvement of aerodynamic modelling to include nonuniform inflow and dynamic stall, and a capability to handle new rotor configurations, such as bearingless rotors. He also recommended the acquisition of additional reliable and detailed experimental data to support the development of improved analytical models.

The most critical instability in a tilt-rotor aircraft is whirl flutter. In addition to rotor and wing dynamics, the engine and transmission dynamics have a major influence on this stability. The interconnecting shaft introduces a differential speed mode with a natural frequency of the same order as the wing mode. Tilt-rotor designs (Bell-Boeing JVX and V22) have two heavy engines, one at each wing tip, and it results in several low frequency wing modes which couple with the proprotor modes. In fact, pylon whirl flutter limits the maximum airspeed of tilt-rotor aircraft. One approach to increasing the flutter speed is to design the wing to prevent the vibratory motion from coupling with the proprotor forces. Alternatively, careful design of proprotor aerodynamics can also increase the stability speed. These two approaches, although appearing simple, are difficult to implement because an accurate knowledge of the vibration characteristics of the vehicle is required and these approaches often lead to expensive solutions. A promising approach for increasing the speed of tilt-rotor aircraft is to use an active control system to suppress the coupling between the wing and proprotor. This can be implemented by adjusting the pitch controls of the proprotor based on feedback of wing motion (Vorwald \& Chopra 1991). To reduce the influence of external disturbances and measurement noise, the model variables are estimated with a Kalman-Bucy filter. An example showed that using the feedback of vertical wing motion, the stability speed of the Bell XV-15 model could be raised by $20 \%$ (figure 25 ).

In summary, available analyses: lack accurate modelling of complex hubs, including bearingless and elastomeric hubs; cannot model adequately composite couplings; use simple modelling for advanced-tip rotors; use very restrictive aerodynamic representation; and incorporate limited degrees of motion for wings and blades. However, because of the growing interest by NASA in a high speed tilt-rotor aircraft, many new research initiatives are taking place which will help to solve these problems. 

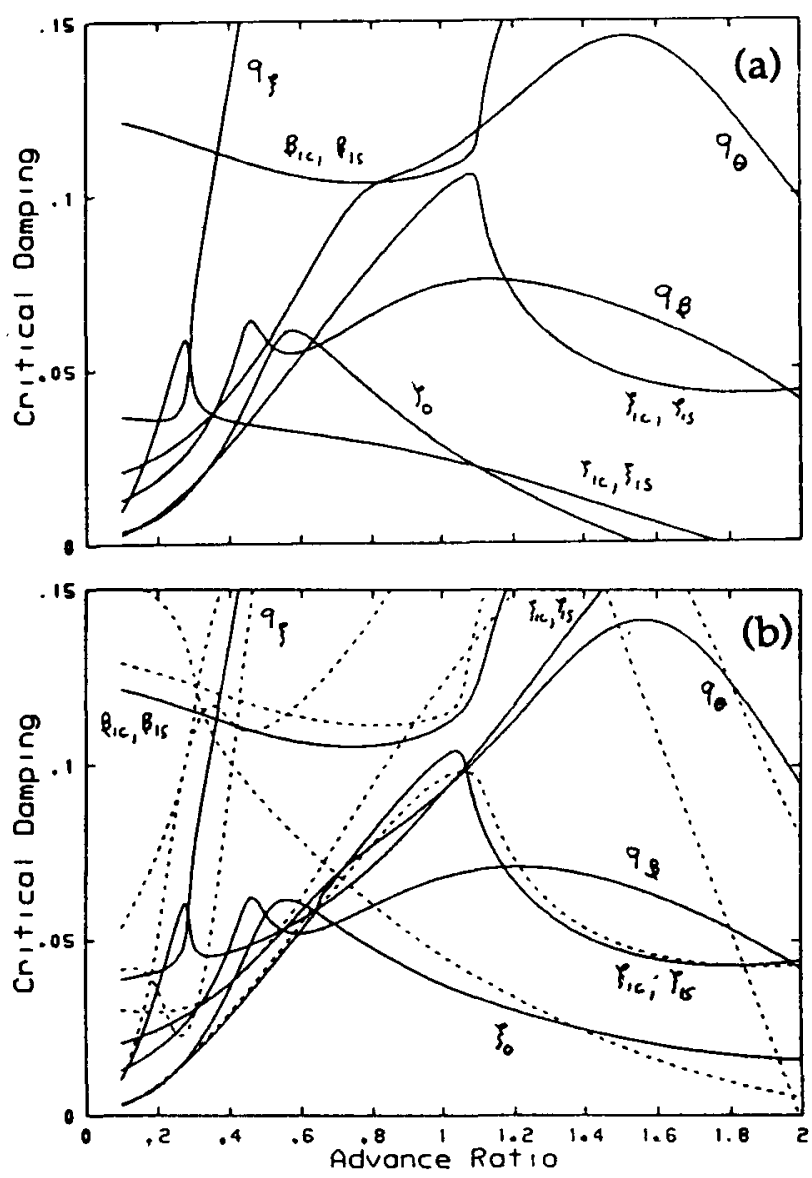

Figure 25. (a) Pylon whirl flutter results (baseline) (Vorwald \& Chopra 1991). (b) Influence of controller on whirl flutter stability (Vorwald \& Chopra 1991).

\section{Advanced geometry rotors}

To enhance the aerodynamic performance of rotors, in particular at high speed flight, advanced-geometry blades are now frequently used (figure 26). These include such features as specialized airfoils, tapered planform and thickness, swept-tips, anhedral-tips, and nonlinear twist distribution. For example, the incorporation of tip sweep reduces the incident tip Mach number normal to the chord and helps reduce the power requirement by reducing the transonic drag rise on the advancing side of the disk. Advanced tips also appear attractive for reduction of vibration and hub loads, for noise reduction, and for enhancement of aeromechanical and flight stability. However, with these advanced-geometry blades, three-dimensional aerodynamic effects become more important, and also, structural analyses need to be refined. Many of the current rotorcraft codes cannot precisely model these advanced geometry blades.

Several researchers involved with rotary-wing aerodynamics have investigated the aerodynamic characteristics of rigid blades with advanced tips (Philippe \& Vuillet 1983; Desopper 1985; Desopper et al 1989). For example, Desopper 1985, using a detailed CFD method, analysed the flow field and pressure distribution on an isolated 

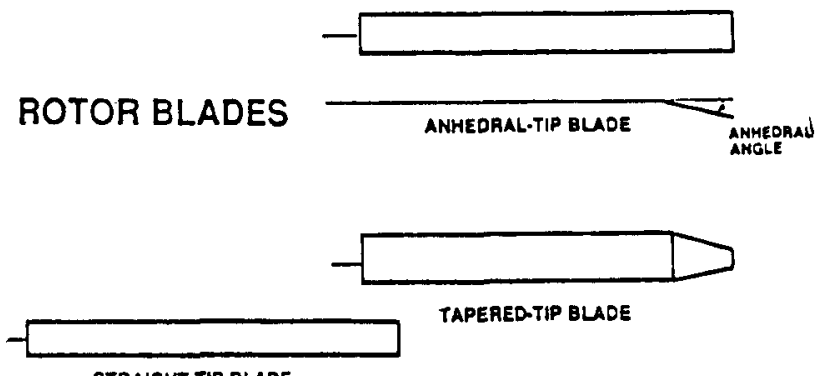

STRAIGMTTTIP QLADE

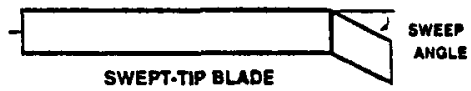

Figure 26. Advanced tip-rotors.

nonlifting blade with advanced tips. It was shown that the use of a combination of sweep and anhedral angle for the tip can reduce the power requirement for the rotor. This study recommended that careful dynamic and structural modelling of the blade be a prerequisite for accurate aerodynamic predictions. Noonan (1985) examined the influence of blade taper ratio and taper initiation point on rotor performance. Using quasisteady aerodynamics, a combination of blade taper, twist and airfoil shape can significantly reduce rotor power.

Some researchers involved with rotor dynamics have addressed the modelling of advanced tips (Panda 1987; Celi \& Friedman 1988a; Benquet \& Chopra 1989; Kim \& Chopra 1992). Celi \& Friedmann (1988a) developed a finite element approach to refine the structural representation of swept-tip blades, and analysed the aeroelastic response and stability of the rotor in forward flight. Comparison of results calculated using an equivalent sweep approximation (by shifting chordwise aerodynamic centre and centre of gravity for tip) and a refined structural model showed considerable discrepancy. They pointed out that the routinely-followed equivalent approximation for the tip is incorrect and may lead to erroneous conclusions. It was shown that tip sweep introduces flap-torsion and lag-axial couplings which may lead to aeroelastic instability associated with frequency coalescence. Panda (1987) derived general transformation and constraint relations between two blade elements joined at an angle to each other. Using these relations, Benquet \& Chopra (1989) developed a finite element formulation to analyse the response of rotors with swept and anhedral tips. Celi \& Friedmann (1988) and Benquet \& Chopra (1989) used quasisteady aerodynamics and only linear transformation relations between the tip and blade were included. Kim \& Chopra (1992) refined the advanced-tip analysis by including detailed threedimensional aerodynamics and nonlinear transformation relations. A finite element rotor dynamic analysis was coupled with finite difference aerodynamic analysis, based on transonic small disturbance theory, to calculate the response, structural bending and loads of elastic blades with tip sweep, anhedral and planform taper. It was shown that tip sweep introduces a kinematic axial-lag coupling and a straightening effect of the centrifugal forces that significantly influence the lag dynamics. For a swept-tip blade, the intensity of transonic flows on the advancing side of the rotor is much reduced as compared to a straight-tip blade and this can help improve rotor power requirement and acoustic signatures (figure 27). Tip anhedral has a considerable influence on flap dynamics. The inclusion of three-dimensional aerodynamics in 

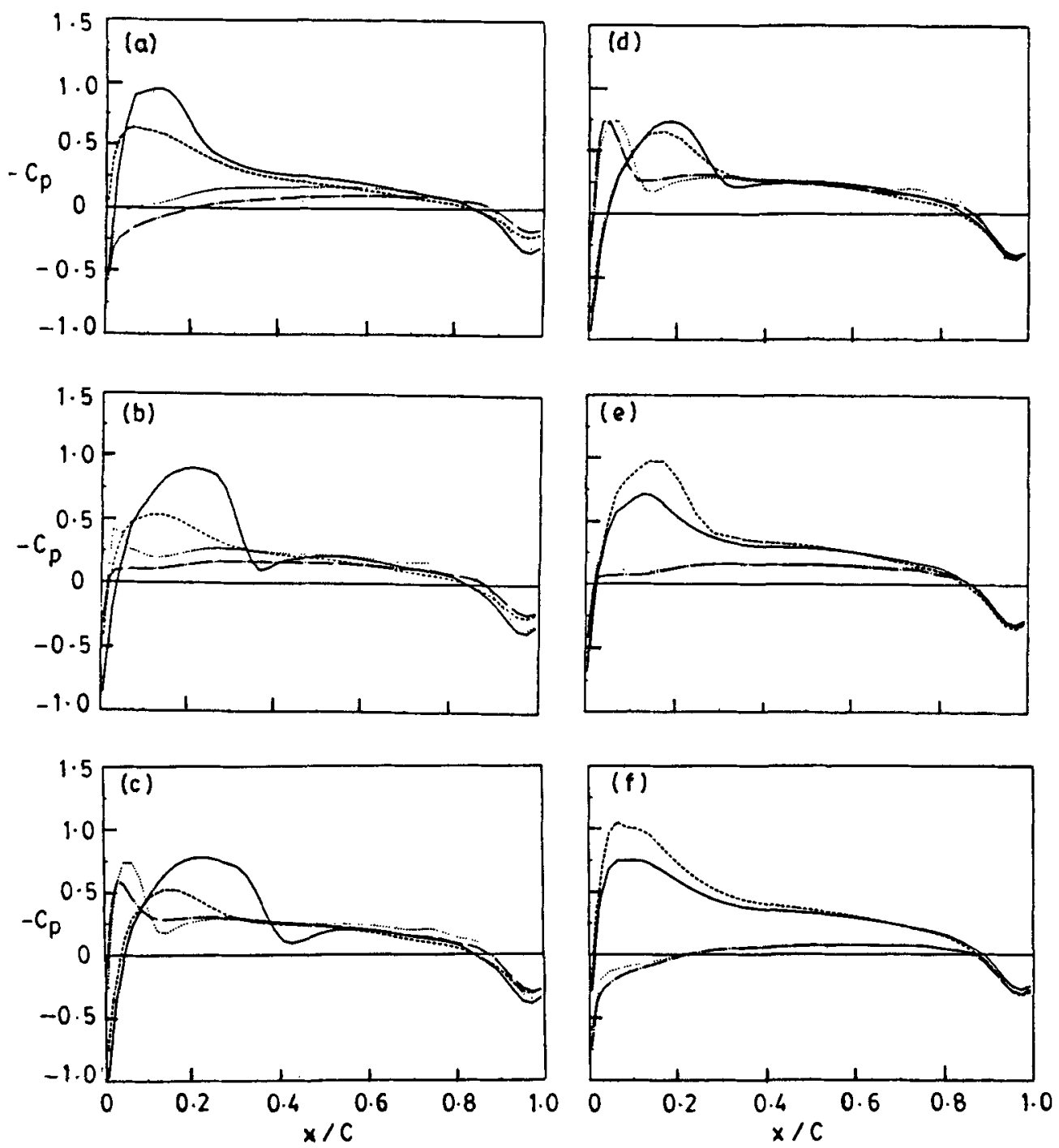

Figure 27. Chord wise pressure distributions of swept-tip $\left(30^{\circ}\right)$ and straight blades at $r / R=0.98, \mu=0.378, C_{T} / \sigma=0.064$, tip $=0.1 \mathrm{R}(\mathrm{Kim} \&$ Chopra 1992). $-\cdot-$ Lower surface (swept tip); - - upper surface (swept tip); ... lower surface (straight tip); upper surface (straight tip). $\Psi=30^{\circ}$ (a), $60^{\circ}$ (b), $90^{\circ}$ (c), $120^{\circ}$ (d), $150^{\circ}$ (e), and $180^{\circ}$ (f).

calculating aerodynamic loads is quite important in order to predict accurately the blade dynamics and loads of an advanced-tip rotor, especially in high-speed flight conditions (figure 28). With a careful selection of tip sweep, anhedral and planform taper, one may design an optimum blade that could improve the performance of a helicopter significantly. 

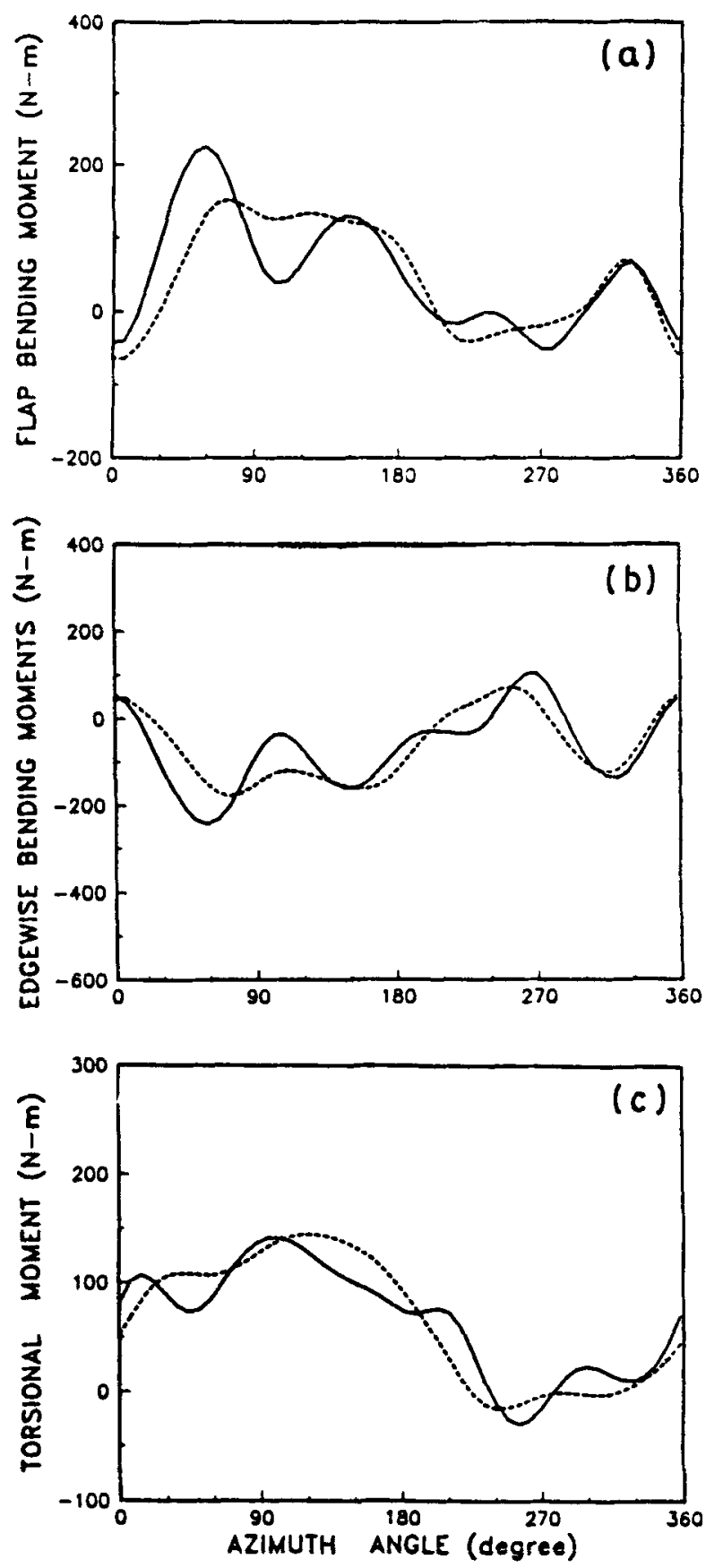

Figure 28. Effect of 3-D aerodynamics on structural bending for a swept-tip blade, tip $=0 \cdot 1 \mathrm{R}$, $\mu=0.378, C_{T} / \sigma=0.064$. (a) Flap bending, (b) lag bending and (c) torsional moments at 0.8 radius (Kim \& Chopra 1992). - - $30^{\circ}$ sweep (2-D aero) and - $30^{\circ}$ sweep (3-D aero).

\section{Optimization methodology}

Helicopters are susceptible to high vibrations, initiated primarily at the rotor blades. One direct approach to reduce vibration is to design a rotor which inherently produces low oscillatory hub leads. By making an optimum selection of structural, 
inertial and aerodynamic characteristics of the blades, it appears possible to minimize the source of vibration and keep the blades aeroelastically stable. An automated methodology used to accomplish this objective is referred to as "aeroelastic optimization."

Aeroelastic optimization has received considerable attention in the fixed-wing field (Ashley 1982). With an enhanced understanding of the dynamics of rotary-wing systems, it is now becoming feasible to apply aeroelastic optimization to rotorcraft. The potential of structural optimization is further expanded with the application of composites in blade construction, which permits great flexibility in tailoring structural characteristics. Also, with the availability of refined optimization algorithms and the substantially increased capability of computers, it is becoming more attractive to implement aeroelastic optimization in the design of complex rotor systems.

Recently, there have been some attempts to apply aeroelastic optimization to helicopter rotors to minimize vibration (for a recent review see Friedman 1991). Blackwell (1983) made a systematic sensitivity study to examine the influence of blade stiffness, spanwise mass distribution, chordwise location of blade centre of gravity, twist, tip sweep and airfoil camber on oscillatory hub loads of a four-bladed articulated rotor. He pointed out the potential of vibration reduction through an optimum blade design. Taylor (1982) considered the vibration reduction of a helicopter through the minimization of a modal shaping parameter. The response of a particular mode to the aerodynamic excitation was minimized by adjusting the mode shape. It is a restrictive approach to reduce vibration. His study was based on simple linear modal analysis, but showed the potential of structural optimization in the rotorcraft field.

Friedmann \& Shanthakumaran (1984) applied a modern structural optimization procedure using a sequential unconstrained minimization technique (Miura \& Schmit 1979) to reduce oscillatory hub loads for a four-bladed hingeless rotor. They imposed constraints on frequency placements and lag mode stability in hover. Through mass and stiffness distributions of blades, a $15-40 \%$ reduction in oscillatory vertical hub shear was achieved for a soft-in-plane hingeless rotor. Peters et al (1986) applied an optimization technique (CONMIN, Vanderplaats 1973) to obtain optimum rotating natural frequencies by distributions of mass and stiffness properties of rotor blades. Then, optimum design was pursued for a minimum blade weight with a constraint of its flap inertia . However, a comprehensive aeroelastic analysis was not considered, and stability constraints were not imposed in the optimization process. Davis \& Weller (1988) used a constrained optimization program called an automated design synthesis (ADS, Vanderplaats et al 1984) to solve four different problems: maximizing bearingless rotor in-plane damping, placing blade natural frequencies, minimizing hub vertical shear and minimizing rotor modal vibration indices. This study was an extension of the work of Taylor (1982) coupled with modern optimization techniques. However, aeroelastic stability constraints were not considered in the optimization process. Davis \& Weller (1991) also conducted two experimental programmes to verify the optimization results. In the first programme, the edgewise structural stiffness of a bearingless rotor model was optimized to maximize lag damping. In the second programme, the blade spanwise mass distribution and structural stiffness of an articulated rotor were optimized to minimize rotor vibratory loads in forward flight. The experimental results verified the reliability of the selected optimization criteria and the potential of the modal-based analysis. Yen (1985) showed that a significant reduction in oscillatory hub loads could be achieved by structural optimization of 
rotor blades, and stressed the importance of the interaction of rotor structural properties with aerodynamic loads for minimization of hub loads. Simplified rotor dynamic equations were used in the analysis. Correlations of limited flight test and wind tunnel data with theory were also discussed. Recently, Chattopadhyay \& Walsh (1989b) applied CONMIN to achieve minimum weight design of a helicopter blade subject to constraints on fundamental coupled flap-lag frequencies and on the autorotational inertia. CAMRAD was used to carry out modal analysis of blades. Significant reduction of blade weight was made possible for both rectangular and tapered box beam structures. In this paper, aerodynamic forces were not included. Recently, Chattopadhyay \& Walsh (1989a) modified their formulation to include aerodynamic and dynamic coupling in forward flight. Results of this' optimization study showed that significant reductions in blade weight and $4 /$ rev vertical hub shear, as well as in oscillatory blade airloads and total rotor power, were possible through the redistribution of the structural characteristrics of blades. Celi \& Friedmann (1988b) carried out a comprehensive optimization study using CONMIN (Vanderplaats 1973) to minimize oscillatory vertical hub shear for a hingeless rotor with both straight and swept tip blades. They imposed constraints on frequency placements and blade stability in hover. This study showed that the introduction of the swept tip could be benefisial in reducing helicopter vibrations. Celi (1991) applied structural optimization to improve the flight mechanics of a hingeless rotor helicopter. Optimizing the distribution of blade torsional stiffness and cross-sectional offsets (c.g. and elastic axis), the phugoid motion was stabilized while imposing constraints on aeroelastic stability, peak-to-peak bending stresses and longitudinal cyclic response.

Aeroelastic optimization of a system essentially consists of determining the optimum values of design variables that minimize the objective function and satisfy certain aeroelastic and geometric constraints. One of the key elements of an optimization analysis is the calculation of the gradients of the objective function, such as hub loads, structural bending and blade response, and the gradients of aeroelastic constraints such as eigenvalues, with respect to design variables. Rotor dynamics is complex and involves nonlinear inertial, elastic and aerodynamic forces. Most of the existing rotor optimization studies use finite difference methods to calculate sensitivity derivatives, and therefore involve substantial computation time to obtain an optimum solution. Because of prohibitively large computation time, these studies are restrictive in terms of objective functions, dynamic constraints and the number of design variables. Recently, Celi \& Friedmann (1988) addressed this issue by building a sequence of approximate optimization problems. This method reduced the total number of function evaluations needed for the calculation of sensitivity derivatives of the objective function and constraints, compared with the conventional finite difference methods.

Lim \& Chopra (1990) have made a concerted effort to efficiently calculate sensitivity derivatives of hub loads and stability eigenvalues using a direct analytical approach (chain-rule differentiation). An innovative formulation was developed for the calculation of the sensitivity derivatives and it formed an integral part of regular response and stability solutions. The derivatives were therefore obtained at a fraction of the computation time compared to the frequently adopted finite difference methods (figure 29). For reduction of helicopter vibration, the objective function involved the minimization of one or more components of oscillatory hub loads. In the case in which more than one component was involved with the objective function, suitable weighting functions were incorporated. The constraints involved the aeroelastic 


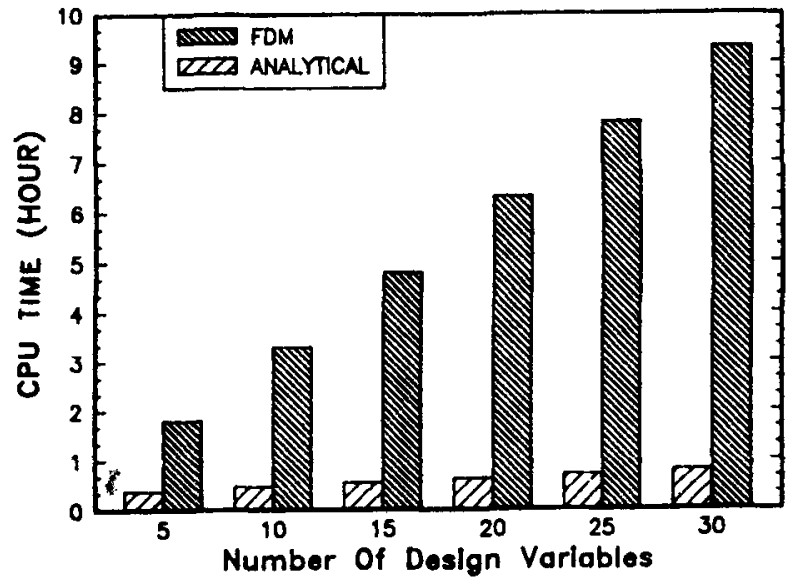

Figure 29. Comparison of CPU time for design sensitivity analysis (Lim \& Chopra 1991).

stability of the blade in forward flight, placement of rotating natural frequencies and autorotational performance of the rotor. For the optimization analysis (Lim \& Chopra $1989,1991)$ an automated optimization process was developed by coupling rotor dynamic analysis and a standard modern optimization code called CONMIN. Optimum solutions were calculated for two types of blade structural representations. One was a generic rotor blade whose structural properties are described in terms of blade stiffness, regardless of the cross-sectional details. In the second type, the blade structural characteristics are defined in terms of a spar geometry of a closed-cell box
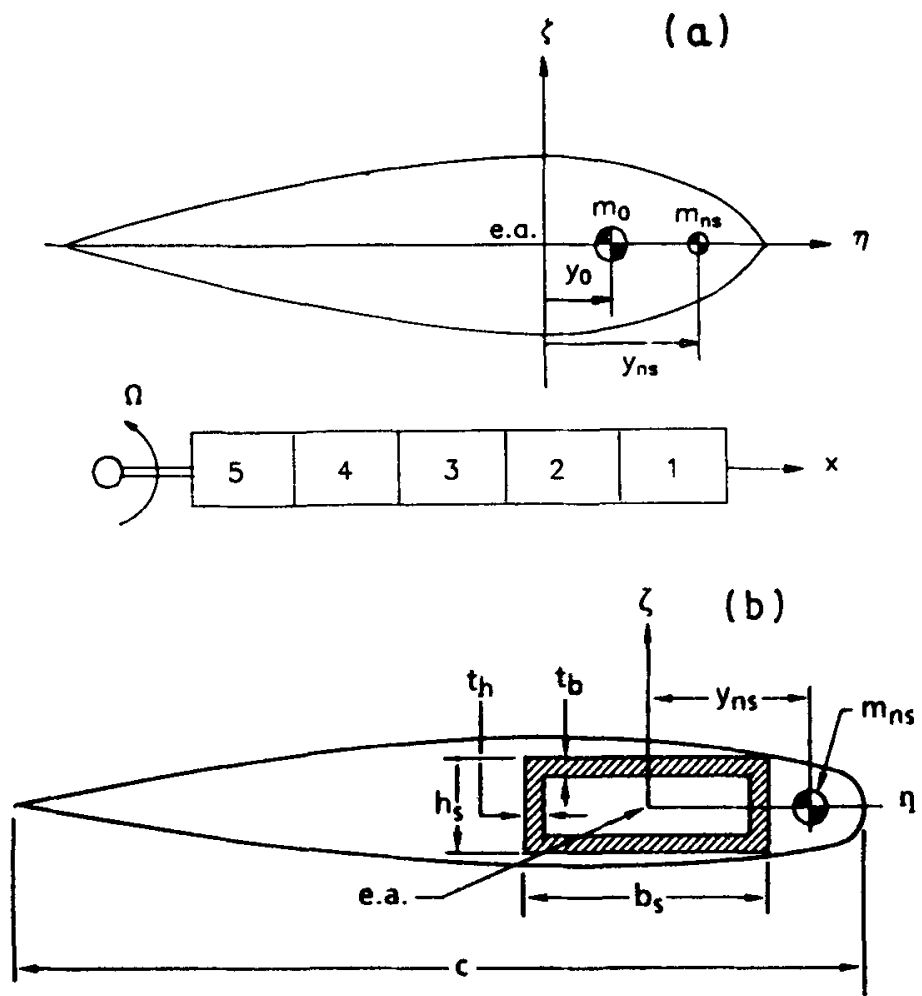

Figure 30. (a) Generic blade and beam elements. (b) Blade cross-section with a box beam. 


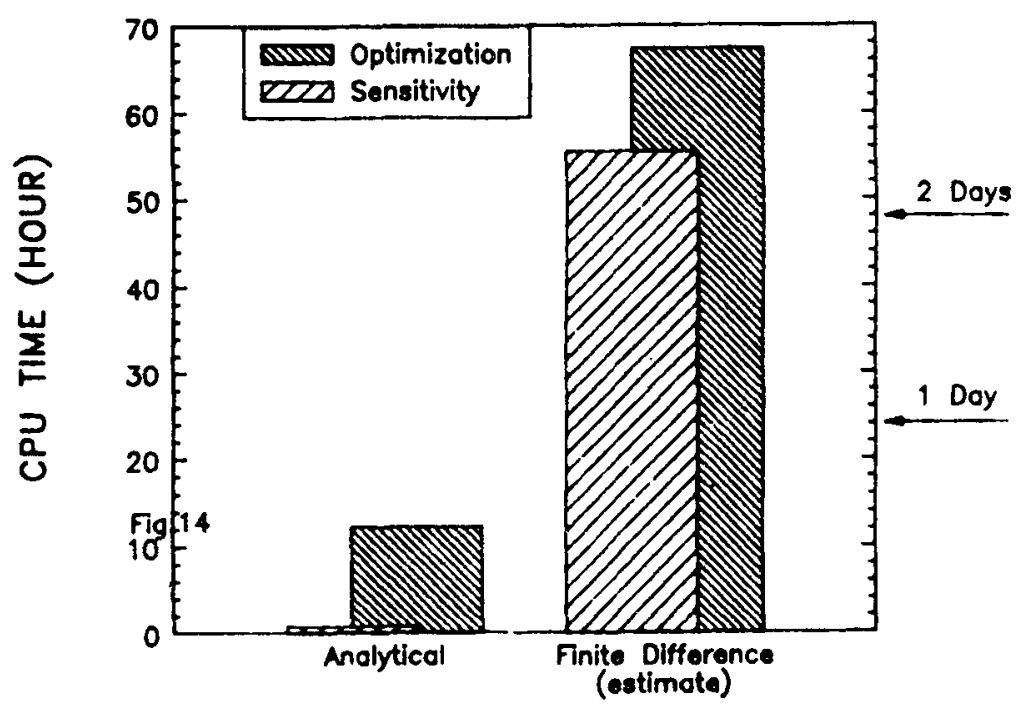

Figure 31. Comparison of CPU time for the optimization procedure (Lim \& Chopra 1989).

beam (figure 30). Structural optimization was carried out on a four-bladed, soft-inplane hingeless rotor to minimize six components of oscillatory hub loads while maintaining lag mode stability in forward flight and certain behaviour constraints. It was shown that the direct analytical approach for sensitivity derivatives resulted in an $80 \%$ reduction in total CPU time compared with commonly used finite difference approaches (figure 31). The minimization of $4 / \mathrm{rev}$ vertical hub shear alone is not sufficient to reduce vibration. The best design solution is achieved by distribution of nonstructural masses and blade-bending stiffnesses (flap, lag and torsion), and removing the blade c.g. as a design variable (figure 32). Optimum solutions resulted in reductions of $25-77 \%$ for a generic blade, and $30-50 \%$ for the box-beam blade relative to baseline values of the objective function that was composed of all six components of hub

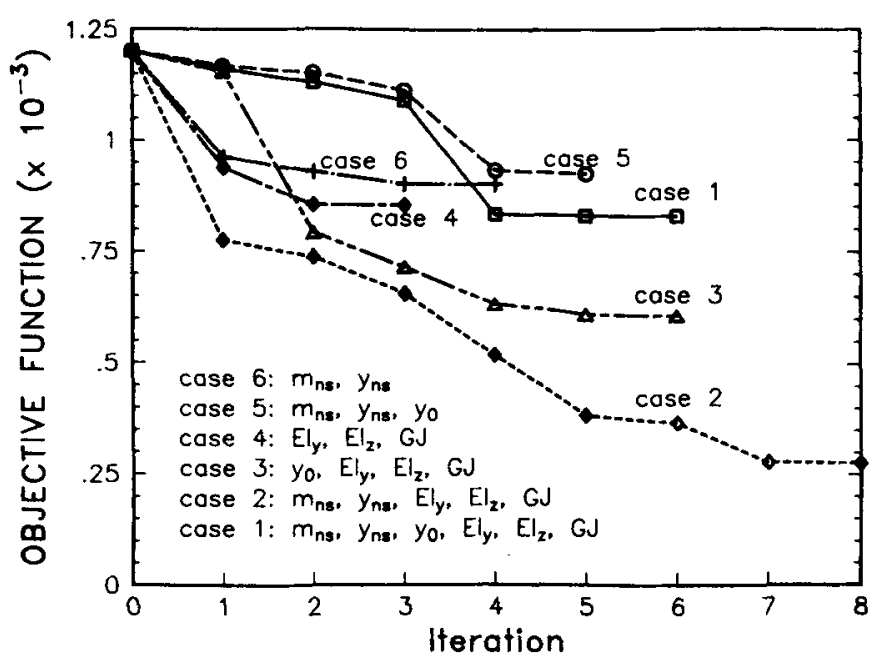

Figure 32. Optimization iteration history of objective function for a generic blade, $C_{T} / \sigma=0.07, \mu=0.3(\operatorname{Lim} \&$ Chopra 1989). 

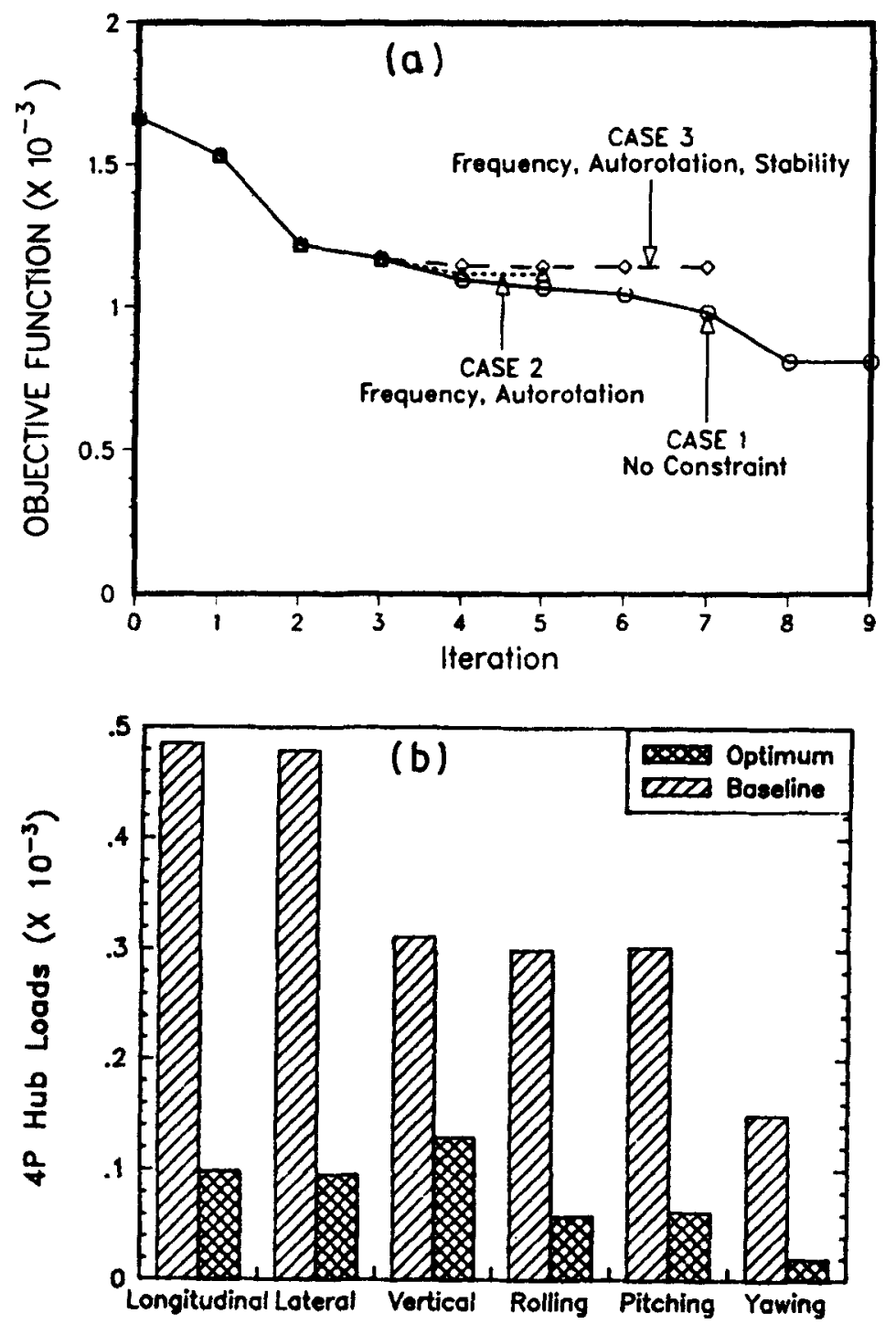

Figure 33. (a) Optimization iteration history of objective function for a box beam blade, $C_{T} / \sigma=0.07, \mu=0.3$, soft-in-plane hingeless rotor (Lim \& Chopra 1991). (b) Optimum 4/rev hub forces and moments (Lim \& Chopra 1991).

loads (figure 33). Ganguli \& Chopra (1992a) showed that using advanced geometry blades such as including distributed sweep, anhedral, pretwist and planform taper, it is possible to achieve additional reduction of $10-15 \%$ of oscillatory hub loads in an optimum rotor design. Sensitivity and optimization analysis of a composite rotor was carried out for a box-beam laminated spar (Ganguli \& Chopra 1992b). Starting from an initially infeasible design, the optimum design solution for a four-bladed soft-in-plane rotor with structurally tailored pitch-lag coupling shows an increase on lag damping of over $100 \%$.

Utilizing the structural optimization methodology, there is great potential for 
designing rotor blades to enhance the efficiency of rotorcraft. It may further expand the optimization potential through the application of composite tailoring and advanced geometry tips. It will be important to check these gains by testing dynamically-scaled optimized rotor models at different flight conditions.

\section{Smart structures technology}

As stated previously, helicopters are susceptible to high vibratory loads, aeromechanical instabilities, excessive noise levels, poor flight stability characteristics, and high dynamic stresses. To reduce these problems to an acceptable level, numerous passive and active devices, and many ad hoc design fixes, are resorted to with resultant weight penalties and reduced payloads. The primary source for all these problems is the nonsteady and complex aerodynamic environment in which the rotor must operate. To counter some of these deficiencies, and also to further expand the flight capabilities of military and civilian helicopters, many new design modifications and devices are being contemplated. These appear to show incremental and modest gains in terms of performance improvement and reduction in operating costs. If the objective is to achieve ' $a$ jet smooth ride' with helicopters at a comparable operating cost, for example, one has to try revolutionary ideas. One innovative idea that may give a substantial jump in performance at a small price is to apply the technology of smart structures to rotorcraft. For such an application, numerous light-weight sensors and actuators are embedded or surface-mounted at different stations on the blades, transmission shafts and airframe, and optimal distributed forces applied with the help of modern control theory. At this stage, the technology of smart structures is primitive and requires a focused basic research effort that will help clarify the projected gains. It is therefore necessary to separate reality from fantasy, practicality from hypothesis, and full-scale possibilities from laboratory models.

A smart structure involves distributed actuators and sensors, and one or more microprocessors that analyse the responses from the sensors and use distributedparameter control theory to command the actuators to apply localized strains. A smart structure has the capability to respond to a changing external environment (such as loads and shape change) as well as to a changing internal environment (such as damage or failure). Many types of actuators and sensors are being considered, such as piezoelectric materials, shape-memory alloys, electrostrictive materials, magnetostrictive materials, electro-rheological fluids and fibre optics. These can be integrated with main load-carrying structures by surface bonding or embedding without causing any significant changes in the structural stiffness of the system. Among these, piezoelectrics are the most popular. They undergo surface elongation (strain) when an electric field is applied across them and produce voltage when surface strain is applied, and thus can be used both as actuators and sensors. Among other materials, shape-memory alloys are gaining rapid recognition as actuators because of the possibility of achieving large excitation forces, and fibre optics are becoming popular as sensors because they can be easily embedded in composite structures with little effect on the material integrity.

Recently, there has been an increase in smart structures research activities. Much of this work is focused on the application of piezoelectric technology to space-related systems, such as the control of vibration of large space structures (Crawley \& de Luis 1987; Anders \& Rogers 1991) and for stable bases for precision pointing in space 
Controllable Camber Blade

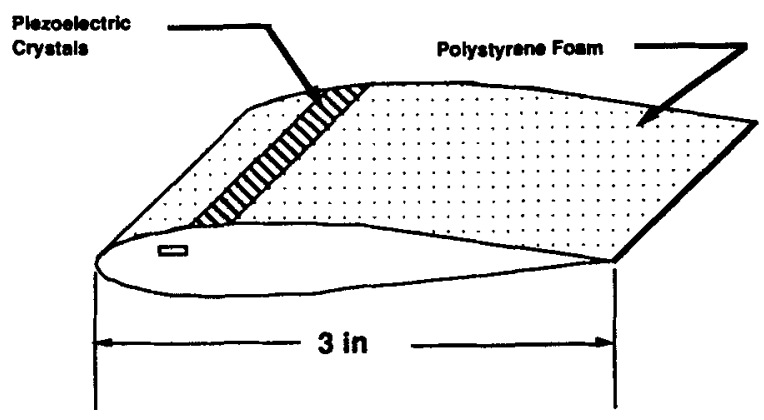

Figure 34. Intelligent rotor model.

(telescope, mirrors etc., Wada et al 1990). Also, there are a few preliminary applications to the field of fixed-wing aircraft, such as controlling wing twist and camber for flutter suppression (Scott \& Weisehaar 1991) and for controlling structure-borne noise (Atluri \& Amos 1989). To date, very little work has been conducted on the use of smart structures for rotorcraft applications. Some of the initial work in applying this emerging technology to the rotor was initiated at Maryland by Barrett (1990). A Froude-scaled two-bladed intelligent rotor model of six-foot diameter was built (figure 34) and tested in the vacuum chamber under rotating conditions. To actively and independently manipulate bending and twist distributions of the blades, directionally attached piezoelectric (DAP) crystals were embedded. Testing of the rotor demonstrated an active tip twist up to $2^{\circ}$ at frequencies as high as $150 \mathrm{~Hz}$ (about

(a)

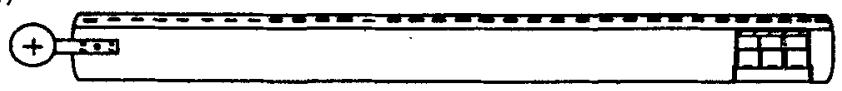

(b)

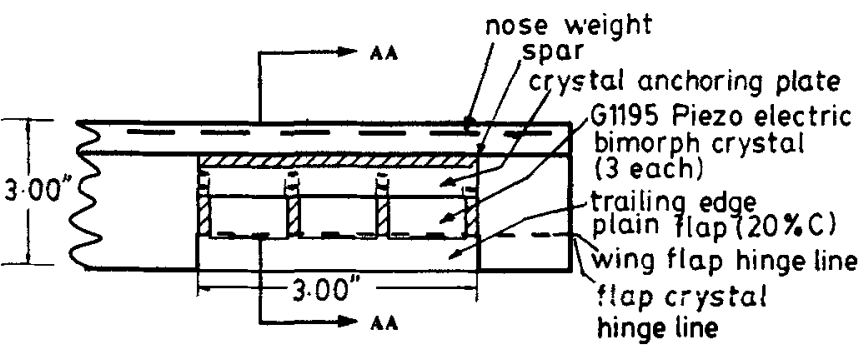

(c)

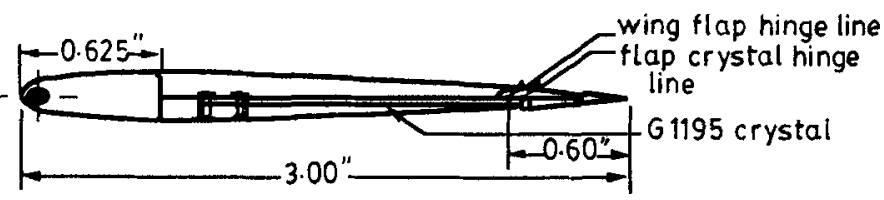

Figure 35. Froude scale rotor model using smart structures technology (Chopra $\&$ Samak 1991). (a) Main rotor blade with flap actuator. (b) Details of flap actuator arrangement. (c) Actuator cross-section AA. 
10 per rev). Using a simple feedback system, it was shown that the forced flapwise vibration of this rotating blade with tip amplitude of about $10 \%$ of radius could be significantly reduced (up to $70 \%$ ). To improve the magnitude of the actuation forces, an alternate model design with a trailing-edge flap is being pursued (figure 35). Through a specially designed mounting arrangement for the flap, small actuation strains of piezo bimorphs are amplified into angular deflections of the flap. It is possible to further improve the actuation by incorporating beneficial composite couplings in design. Also, a Froude scale bearingless rotor model is being built incorporating the smart structures technology to augment aeromechanical stability (figure 36). At the Massachusetts Institute of Technology, Spangler \& Hall (1990) also built a blade model using piezoelectric actuators on a trailing edge flap. Though it was not dynamically scaled or meant to be tested in a rotating environment, it showed the promise of piezo-actuators. At Georgia Tech, Hanagud \& Nagesh Babu (1991) also have been trying to apply piezoelectric technology to reduce the forced vibration of a cantilevered beam specimen. Again, it was not a scaled model, nor were issues related to the rotating environment addressed. Unless testing is carried on with a simulated scaled model, one may not be able to appreciate the actuation force requirement for an actual rotor system. Also, there are several unique and complex issues related to the implementation of smart structure technology in rotorcraft, such as feeding high voltage signals to different actuators in the rotating environment, the need for high force-high strain actuators, the need for small-size and light-weight smart structures, and for tight control on the structural integrity of blades. Unless these issues are addressed in research, one may arrive at false conclusions. To carry out a meaningful study on this topic, one must demonstrate this technology on a dynamically scaled rotor model in the rotating environment.

The structural, mechanical and aerodynamic complexity and the multidisciplinary nature of rotorcraft offer many opportunities for the application of smart structures technology with the potential for very substantial payoffs in system effectiveness. The rotor is the key subsystem, setting the current limits on vehicle performance, handling qualities and reliability. Since the rotor is also a flexible structure, changes in shape, mechanical properties and stress/strain fields can be imposed upon it. These in turn will alter the vibratory modes, aeroelastic interactions, aerodynamic properties, and dynamic stresses of the rotor and fuselage. Smart structures technology will enable these imposed changes to be tailored to conditions sensed in the rotor itself.

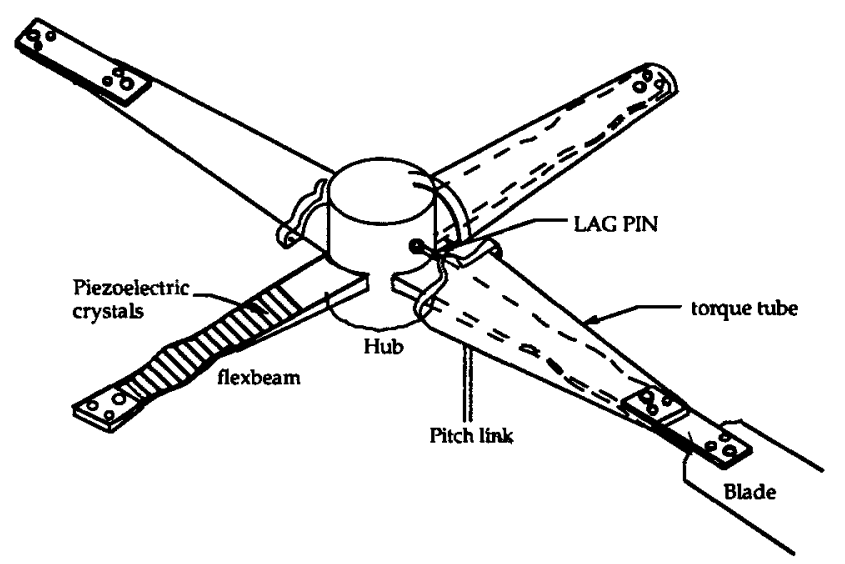

Figure 36. Aeromechanical stability augmentation in a bearingless rotor $(6 \mathrm{ft}$ dia) using smart structures technology. 
Furthermore, because the smart actuators and sensors can be distributed over each individual rotor blade, control can be imposed over a much larger bandwidth than with current swashplate-based controls which are limited to $N / \mathrm{rev}$ for an $N$-bladed rotor. This opens up a hitherto unavailable domain for vibrational control, aeromechanical stability augmentation, handling quality enhancement, and reduction of acoustic signatures. The use of smart structures also offers the prospect of sensing structural damage in the rotor structure and in other critical components. The pilot can then be alerted, enabling him/her to take load alleviation action. There also exists the potential for altering the stress field following damage, using smart materials. This could provide a degree of self-repair. A further very promising application of smart structures is to control the critical frequency of drive shafts.

Basic smart structures technology rlso needs to be advanced if the potential for use on rotocraft is to be fully realizeu. Most critically, we need new concepts for smart actuators with high strain rates, large bandwidths and minimum impact on the host structure. We need better understanding of the transfer functions and failure modes of the smart devices themselves. We need new, rapid, robust algorithms for control systems involving multiple, distributed sensors and actuators.

In order to realise the potential advantages of smart structures for rotorcraft, an integrated research effort is required. This research should investigate the exploitation of smart structure concepts in a realistic environment, emulating that of the rotorcraft, and advance the underlying generic smart structure concepts and technologies that could benefit rotorcraft. This integrated approach is essential if the problems limiting the application of smart structures are to be identified, and if fundamental research efforts are to be properly focused.

\section{Conclusions and recommendations for future work}

Hingeless and bearingless rotors: For an accurate analysis of bearingless rotors, one needs to incorporate finite element discretization, and modelling of redundant load paths and large elastic deflections. These rotors suffer from air resonance instability, and to stabilize this, innovative designs must be explored to achieve beneficial aeroelastic couplings.

Composite rotors: For analysis of composite blades, nonclassical effects such as section warping, transverse shear, and in-plane elasticity become important and must be included. For open-section beams, modelling of warping constraints must also be incorporated. Systematic experimental testing of simple composite beams in rotating and nonrotating environments is needed to validate analyses. The potential for tailoring of structural couplings to minimize blade stresses and vibration and to increase aeromechanical stability must be explored.

Circulation control rotor: Trailing-edge blowing has a powerful influence on the dynamics and flight mechanics of fixed-wing and rotary-wing airplanes. For proper CC rotor analysis, the perturbation, unsteady and pneumodynamics effects associated with blowing must be incorporated. Circulation control aerodynamics causes some new aeroelastic instabilities, such as blowing flutter and control reversal, and these must be explored systematically. The state of art on $\mathrm{CC}$ technology is quite primitive 
and reliable mathematical tools need to be developed before it can be exploited in rotorcraft.

Tilt-rotors: The dynamics of a tilt-rotor is more involved than a conventional rotor because of complex couplings due to wing and pylon motion, high inflow ratio in airplane mode, highly twisted blades and tilting of main rotors. For an accurate prediction of the dynamic instability, it is important to include blade bending flexibility, proper modelling of rotor hub, pylon and wing motion, and proper representation of gimbal and rotor-speed degrees of freedom. The potential of an active feedback system to augment whirl flutter instability must be investigated.

Advanced geometry rotors: For accurate analysis of advanced geometry rotors, it is necessary to develop special finite elements for the tip including nonlinear transformation relations between main blade and tip and three dimensional aerodynamics. Advance tips such as swept, anhedral and tapered-planform have significant influence on dynamics, performance and acoustic signatures. Utilizing automated optimization methodology, tip geometry must be explored to improve rotor efficiency.

Structural optimization methodology; For practical applications of structural optimization in rotorcraft, it is essential to develop an efficient sensitivity analysis. For minimization of rotorcraft vibration, it is needed to minimize an objective function consisting of all rotor hub leads. The domain of optimization must be expanded to cover flight mechanics and basic performance and to utilize composite tailoring and advanced geometry tips.

Smart structures technology: At this time, this technology is primitive and a focussed research effort is needed before it can be exploited in rotorcraft. It is necessary to develop light-weight actuators with high strain and band width, formulate robust control algorithms for distributed actuators and sensors and check implementation in rotating environments.

\section{References}

Anders W S, Rogers C A 1991 Design of a shape memory alloy deployment hinge for reflector facets. Proceedings of the AIAA/ASME/ASCE/AHS/ASC 32nd Structures, Structural Dynamics and Materials Conference, Baltimore, Maryland

Ashley H 1982 On making things the best - aeronautical uses of optimization. J. Aircraft 19: 5-28

Atluri S N, Amos A K (eds) 1989 Large space structures: Dynamics and control (Berlin: Springer Verlag)

Barnes D R, Bill F A, Wilkerson J B 1979 Circulation control flight domonstrator test program. Proceedings of the 35th Annual Forum of the American Helicopter Society, Washington, DC

Barrett R 1990 Intelligent rotor blade and structures development using directionally attached piezoelectric crystals. Master of Science thesis, Department of Aerospace Engineering, University of Maryland, College Park

Bauchau O A, Hong C H 1988 Nonlinear composite beam theory. J. Appl. Mech. 55: 156-163

Benquet P, Chopra I 1989 Calculated dynamic response and loads for an advanced tip rotor in forward flight. Proceedings of the Fifteenth European Rotorcraft Forum, Amsterdam, Netheriands 
Bir G S, Chopra 11991 Effect of nonlinear elastomeric dampers on aeromechanical stability of helicopters. Proceedings of the International Technical Specialists Meeting on Rotorcraft Basic Research, Georgia Tech, Atlanta

Blackwell R H 1983 Blade design for reduced helicopter vibration. J. Am. Helicopter Soc. 28: 33-41

Celi R 1991 Optimization aeroelastic design of helicopter rotors for longitudinal handling qualities improvement. J. Aircraft 28: 49-57

Celi R, Friedmann P P 1988a Aeroelastic modeling of swept tip rotor blades using finite elements. J. Am. Helicopter Soc. 33: 43-52

Celi R, Friedmann P P 1988b Structural optimization with aeroelastic constraints of rotor blades with straight and swept tips. Proceedings of the 29th AIAA Structures, Structural Dynamics and Materials Conference, Williamsburg, Virginia

Chandra R, Chopra I 1991a Experimental and theoretical analysis of composite I-beams with elastic couplings. AIAA J. 29: 2197-2205

Chandra R, Chopra I 1991b Vibration characteristics of composite I-beams with elastic couplings under rotation. Proceedings of $47 \mathrm{th}$ Annual Forum of American Helicopter Society, Phoenix, Arizona

Chandra R, Chopra I 1992a Influence of elastic couplings on vibration characteristics of thin-walled composite box beams under rotation. J. Aircraft 29: 657-664

Chandra R, Chopra I 1992b Structural response of composite beams and blades with elastic couplings. Compos. Eng., Int. J. 2: 347-374

Chandra R, Stemple A D, Chopra I 1990 Thin-walled composite beams under bending, torsional and extensional loads. J. Aircraft 27: 619-626

Chattopadhyay A, Walsh J L 1989a Integrated aerodynamic/dynamic optimization of helicopter rotor blades. Proceedings of the 30th AIAA Structures, Structural Dynamics and Materials Conference, Mobile, Alabama

Chattopadhyay A, Walsh J L $1989 \mathrm{~b}$ Minimum weight design of helicopter rotor blades with frequency constraints. J. Am. Helicopter Soc. 34: 77-82

Cheeseman I C 1967 The application of circulation control by blowing to helicopters. J. $R$. Aeronaut. Soc. 71: July

Chen W Y, Chopra I 1991 Aeromechanical stability of helicopters in forward flight. Proceedings of the International Technical Specialists Meeting on Rotorcraft Basic Research, Georgia Tech, Atlanta

Chopra I 1984 Aeroelastic stability of an elastic circulation control rotor blade in hover. Vertica 8: 353-371

Chopra I 1985 Aeroelastic stability of a bearingless circulation control rotor blade in hover. J. Am. Helicopter Soc. 30: 40-47

Chopra I 1988 Aeroelastic stability of a bearingless circulation control rotor in forward flight. J. Am. Helicopter Soc. 33: 60-67

Chopra I 1990 Perspectives in aeromechanical stability of helicopter rotors. Vertica 14: 457-508

Chopra I, Johnson W 1979 Flap-lag-torsion aeroelastic stability of circulation control rotors in hover. J. Am. Helicopter Soc. 23: 37-46

Chopra I, Samak D K 1991 Development of an intelligent rotor. Conference on Active Materials and Adaptive Structures, Arlington, Virginia

Crawley E F, de Luis J 1987 Use of piezoelectric actuators as elements of intelligent structures. AIAA J. 25: 1373-1385

Davis M W, Weller W M 1988 Application of design optimization techniques to rotor dynamics problems. J. Am. Helicopter Soc. 33: 42-50

Davis M W, Weller W H 1991 Helicopter rotor dynamics optimization with experimental verification. J. Aircraft 28: $38-48$

Desopper A 1985 Study of unsteady transonic flow on rotor blade with different tip shapes. Vertica 9: No. 3, July

Desopper A, Lafon P, Ceroni P, Philippe J J 1989 Ten years of rotor flow studies at ONERA. J. Am. Helicopter Soc. 34: 41-51

Dull A L, Chopra I 1988 Aeroelastic stability of bearingless rotors in forward flight. J. Am. Helicopter Soc. 33: 38-46

Englar R J, Applegate C A 1984 Circulation control - A bibliography of David Taylor Naval 
Ship Research and Development Center Research and selected outside references. Report DTNSRDC 84/052, AD A146-966, September

Englar R F, Trobaugh L A, Hemmerly R A 1978 sToL potential of the circulation control wing for high performance aircraft. J. Aircraft 15: 175-181

Friedmann $P$ P 1991 Helicopter vibration reduction using structural optimization with aeroelastic/multidisciplinary constraints - A survey. J. Aircraft 28: 8-21

Friedmann P P, Shanthakumaran P 1984 Optimum design of rotor blades for vibration reduction in forward flight. J. Am. Helicopter Soc. 29: 70-80

Ganguli R, Chopra I 1992a Aeroelastic optimization of an advanced geometry helicopter rotor. Proceedings of the 33rd AIAA/ASME/ASCE/AHS/ASC Structures, Structural Dynamics and Materials Conference, Dallas, Texas

Ganguli R, Chopra I 1992b Aeroelastic optimization of a composite helicopter rotor. Fourth AIAA/USAF/NASA/OAI symposium on Multidisciplinary Analysis and Optimization Conference, Cleveland, Ohio

Ghee T A, Leishman J G 1990 Effects of unsteady blowing on the lift of a circulation controlled cylinder. J. Am. Helicopter Soc. 35: 22-31

Haas D J, Chopra I 1988 Static aeroelastic characteristics of circulation control wings. J. Aircraft 25: 948-954

Haas D J, Chopra I 1989a Flutter of circulation control wings. J. Aircraft 26: 373-381

Haas D J, Chopra I 1989b Aeroelastic stability of aricraft with circulation control wings. Proceedings of the 30th AIAA Structures, Structural Dynamics and Materials Conference, Mobile, Alabama

Hanagud S, Nagesh Babu G L 1991 Smart structures in the control of airframe vibrations. Proceedings of the International Technical Specialists' Meeting on Rotorcraft Basic Research, Georgia Institute of Technology, Atlanta, Georgia

Hodges D H, Atilgan A R, Fulton M V, Rehfield L W 1989 Dynamic characteristics of composite beam structures. Proceedings of the National Technical Specialists Meeting on Rotorcraft Dynamics (Arlington, TX: Am. Helicopter Soc.)

Hong C H, Chopra I 1985 Aeroelastic stability of a composite rotor blade. J. Am. Helicopter Soc. 30: 57-67

Hong C H, Chopra I 1986 Aeroelastic stability analysis of a composite bearingless rotor blade. J. Am. Helicopter Soc. 31: 29-35

Jang J, Chopra I 1988 Air resonance of an advanced bearingless rotor in forward flight. Second International Conference on Rotorcraft Basic Research, College Park, Maryland

Jang J, Chopra I 1989 Ground and air resonance of an advanced bearingless rotor in hover. J. Am. Helicopter Soc. 33: 20-29

Johnson W 1974a Dynamics of tilting proprotor aircraft in cruise flight. NASA TN D-7677

Johnson W 1974b Analytical model for tilting proprotor aircraft dynamics, including blade torsion and coupled bending modes, and conversion mode operation. NASA TM X-62,369

Johnson W 1975 Analytical modeling requirements for tilting proprotor aircraft dynamics. NASA TN D-8083

Johnson W 1980 A comprehensive analytical model for rotorcraft aerodynamics and dynamics. NASA TM-81182

Johnson W 1981 Development of a comprehensive analysis for rotorcraft. Vertica 5: 99-130

Johnson W 1984 An assessment of the capability to calculate tilting proprotor aircraft performance, loads, and stability. NASA Technical Paper 2291

Johnson W 1985 Recent developments in the dynamics of advanced rotor systems. NASA Technical Memorandum 86669

Johnson W, Chopra I 1979 Calculated hovering helicopter flight dynamics with a circulationcontrolled rotor. J. Aircarft 16: 124-128

Kim K C, Chopra I 1992 Aeroelastic analysis of rotor blades with advanced tip shapes. $J$. Am. Helicopter Soc. 38: 15-30

Kosmatka J B, Friedmann P P 1988 Structural dynamic modeling of advanced composite propellers by the finite element method. Proceedings of the 28th AIAA/ASME/ASCE/AHS/ ASC Structures, Structural Dynamics and Materials Conferences; Mobile, Alabama

Kvaternik R G 1973 Studies in tilt-rotor vToL aircraft aeroelasticity. Ph D dissertation, Case Western University

Lim J W, Chopra I 1989 Aeroelastic optimization of a helicopter rotor. J. Am. Helicopter Soc. 34: 52-62 
Lim J W, Chopra I 1990a Response and hub loads sensitivity analysis of a helicopter blade. AIAA J. 28: 75-82

Lim J W, Chopra I 1990b Stability sensitivity analysis for aeroelastic optimization of a helicopter rotor. AIAA J. 28: 1089-1097

Lim J W, Chopra I 1991 Aeroelastic optimization of a helicopter rotor using efficient sensitivity analysis. J. Aircraft 28: $29-37$

Linden A W, Biggers J C 1985 X-Wing potential for navy applications. Proceedings of the 41st Annual Forum of the American Helicopter Society, Fort Worth, Texas

Logan A H 1982 Design and flight test of the no tail rotor (NOTAR) aircraft. Proceedings of the 38th Annual Forum of the American Helicopter Society, Anaheim, California

Lorber P F, Carson R G 1989 The aerodynamics of an oscillating jet flap. J. Am. Helicopter Soc. 34: 24-32

McNulty M J, Bousman W G (eds) 1983 Proceedings of the Integrated Technology Rotor Methodology Assessment Workshop, sponsored by NASA Ames Research Center and the US Army, NASA Conference Publication 10007, June 21-22

Minguet P, Dugundji J 1990a Experiments and analysis for composite blades under large deflections. Part 1: Static behavior. AIAA J. 28: 1573-1579

Minguet $P$, Dugundji J $1990 \mathrm{~b}$ Experiments and analysis for composite blades under large deflections. Part 2: Dynamic behavior. AIAA J. 28: 1580-1588

Miura H, Schmit L A 1979 NEWSUMT - A Fortran program for inequality constrained function minimization. User's Guide, NASA CR 159070

Nixon M W 1989 Extensional-twist coupling of composite circular tubes with application to tilt rotor blade design. Proceedings of the 28th AIAA/ASME/ASCE/AHS/ASC Structures, Structural Dynamics and Materials Conference, Mobile, Alabama

Noonan K W 1985 Aerodynamic design of a helicopter main rotor blade with consideration of flap-lag flutter in hover. M S thesis, University of Maryland

Panda B 1987 Assembly of moderate-rotation finite elements used in helicopter rotor dynamics. Technical Note. J. Am. Helicopter Soc. 32: 63-69

Panda B, Chopra I 1987 Dynamics of composite rotor blades in forward flight. Vertica 11: $187-210$

Peters D A, Rossow M P, Korn A, Ko T 1986 Design of helicopter rotor blades for optimum dynamic characteristics. Comput. Math. Appl. A12: 85-110

Philippe J J, Vuillet A 1983 Aerodynamic design of advanced rotors with new tip shapes. Proceedings of the 39th Annual Forum of the American Helicopter Society, St. Louis, Missouri, pp. 267-277

Popelka D, Sheffler M, Bilger J 1985 Correlations of stability test results and analysis for the 1/5 scale V-22 aeroelastic model. Proceedings of 41 st Annual Forum of American Helicopter Society, Ft. Worth, Texas

Raghavan V, Pai S, Chopra I 1988 Circulation control airfoils in unsteady flow. J. Am. Helicopter Soc. 33: 28-37

Reader K R, Kirkpatrick D G, Williams R M 1978 Status report on advanced development program utilizing circulation control rotor technology. Proceedings of the Fourth European Rotorcraft and Powered Lift Aircraft Forum, Stresa, Italy

Rehfield L W, Atilgan A R, Hodges D H 1990 Nonclassical behavior of thin-walled composite beams with closed cross-sections. J. Am. Helicopter Soc. 35: 42-50

Scott R C, Weisshaar T A 1991 Controlling panel flutter using adaptive materials. Proceedings of the AIAA/ASME/ASCE/AHS/ASC 32nd Structures, Structural Dynamics and Materials Conference, Baltimore, Maryland

Sivaneri N T, Chopra I 1984 Finite element analysis for bearingless rotor blade aeroelasticity. J. Am. Helicopter Soc. 29: 42-51

Smith E C, Chopra I 1991 Formulation and evaluation of an analytical model for composite box beams. J. Am. Helicopter Soc. 36: 23-35

Smith E C, Chopra I 1992a Aeroelastic response and blade loads of a composite rotor in forward flight. Proceedings of the 33rd AIAA/ASME/ASCE/AHS/ASC Structures, Structural Dynamics and Materials Conference, Dallas, Taxas

Smith E C, Chopra I 1992b Aeromechanical stability of helicopters with composite rotors in forward flight. Proceedings of 48th Annual Forum of American Helicopter Society, Washington $\mathrm{DC}$ 
Spangler R, Hall S 1990 Piezoelectric actuators for helicopter rotor control. Proceedings of AlAA/ASME/ASCE/AHS/ASC 31st Structures, Structural Dynamics and Materials Conference, Long Beach, California

Stemple A D, Lee S W, 1988 A finite element model for composite beams with arbitrary cross sectional warping. $A I A A$ J. 26: 1520-1520

Taylor R B 1982 Helicopter vibration reduction by rotor blade model shaping. Proceedings of the 38th Annual Forum of the American Helicopter Society, Anaheim, California

Vanderplaats G N 1973 CONMIN - A Fortran program for constrained function minimization. User's Manual, NASA TMX 62282

Vanderplaats G N, Sugimoto H, Sprague C M 1984 ADS-1: A new general purpose optimization program. $A I A A J .22: 1458-1460$

Vorwald J G, Chopra I 1991 Stabilizing pylon-whirl flutter on a tilt-rotor aircraft. Proceedings of AIAA/ASME/AHS/ASC 32nd Structures, Structural Dynamics and Materials Conference, Baltimore, Maryland

Wada B K, Fanson J L, Crawley E F 1990 Adaptive structures. Proceedings of the ASME Winter Annual Meeting, December

Wang J M, Chopra I 1990 Bearingless rotor aeromechanical stability measurements and correlations using nonlinear aerodynamics. 16th European Rotorcraft Forum, Glasgow, Scotland

Wang J, Chopra I, Samak D K, Green M, Graham T 1989 Theoretical and experimental investigation of aeroelastic stability of an advanced bearingless rotor in hover and forward flight. Proceedings of the National Technical Specialists' Meeting on Rotorcraft Dynamics, (Arlington, TX: Am. Helicopter Soc.)

Wang J, Jang J, Chopra I 1990 Air resonance of hingeless rotors in forward flight. Vertica 14: 123-136

Watkins C B, Reader K R, Dutta S K 1985 Pneumodynamic characteristics of a circulation control rotor model. J. Am. Helicopter Soc. 30: 23-31

Yen J G 1985 Coupled aeroelastic hub loads reductions. AHS/NAI International Seminar, Nanjing, China 